\title{
Insulin glargine in the management of diabetes mellitus: an evidence-based assessment of its clinical efficacy and economic value
}

\author{
Rhian Clissold ${ }^{1}$, Steve Clissold ${ }^{2}$ \\ ${ }^{1}$ Endocrinology Department, Frenchay Hospital, Bristol, UK; ${ }^{2}$ Content Ed Net Communications S.L., \\ Madrid, Spain
}

\begin{abstract}
Introduction: Diabetes is a chronic disease associated with high morbidity and mortality, which represents a major public health concern. Interventions that can enhance patient care and reduce clinic visits will not only relieve some of this burden, they will also improve patient QOL and wellbeing.
\end{abstract}

Aims: This review assesses the evidence for the use of insulin glargine in type 1 and type 2 diabetes mellitus.

Evidence review: Once-daily insulin glargine has a prolonged, peakless activity profile, making it a candidate as a long-acting (basal) insulin. In combination with bolus insulin to cover prandial glucose surges, it facilitates a more physiologic approach to patient management. Evidence from large, randomized, controlled clinical trials in patients with type 1 diabetes has confirmed its effectiveness and tolerability relative to neutral protamine hagedorn (NPH) insulin, with a tendency toward causing less hypoglycemia. In patients with type 2 diabetes requiring insulin therapy, once-daily insulin glargine has proven to be clinically superior to NPH insulin in terms of providing at least as effective glycemic control, but with significantly fewer episodes of nocturnal hypoglycemia. A variety of economic analyses have confirmed the cost effectiveness of insulin glargine in type 1 and type 2 diabetes and in particular it was shown to be significantly superior to NPH insulin.

Clinical value: Insulin glargine has established itself as a first-line choice in patients with type 1 diabetes, including children ( $>6$ years) and adolescents, and is a recommended treatment option. In patients with type 2 diabetes it is clearly associated with less hypoglycemia than NPH insulin, and this may help overcome one of the major barriers to starting insulin therapy in this class of patient. Thus, insulin glargine is a valuable addition to the therapeutic armamentarium available to physicians and it has the potential to significantly improve the quality of life of patients with diabetes.

Core Evidence. 2007;2(2):89-110.

Key words: evidence-based review, glycemic control, insulin glargine, insulin therapy, type 1 diabetes, type 2 diabetes

Core evidence clinical impact summary for insulin glargine in the management of type 1 and type 2 diabetes mellitus

\begin{tabular}{|c|c|c|}
\hline Outcome measure & Evidence & Implications \\
\hline \multicolumn{3}{|l|}{ Patient-oriented evidence } \\
\hline Improved quality of life & Substantial & $\begin{array}{l}\text { Using various rating scales IG was found to be better than NPH insulin in type } 1 \text { patients, and better } \\
\text { than pioglitazone and rosiglitazone in type } 2 \text { patients }\end{array}$ \\
\hline Improved patient satisfaction & Substantial & Patient acceptance and wellbeing was frequently reported and confirmed in a number of RCTs \\
\hline \multicolumn{3}{|l|}{ Disease-oriented evidence } \\
\hline Effective glycemic control in type 1 diabetes & Clear & IG is at least as effective as NPH insulin \\
\hline $\begin{array}{l}\text { Lower incidence of hypoglycemia in } \\
\text { type } 1 \text { diabetes }\end{array}$ & Substantial & Trend in many studies was for a lower incidence with IG than with NPH \\
\hline Effective glycemic control in type 2 diabetes & Clear & IG was at least as effective as NPH insulin, other insulin regimens, and rosiglitazone or pioglitazone \\
\hline $\begin{array}{l}\text { Lower incidence of hypoglycemia in } \\
\text { type } 2 \text { diabetes }\end{array}$ & Clear & Significantly less hypoglycemia with IG than with NPH insulin \\
\hline \multicolumn{3}{|l|}{ Economic evidence } \\
\hline Cost effectiveness in type 1 diabetes & Clear & $\begin{array}{l}\text { A number of RCTs and large observational studies have established the cost effectiveness of IG and } \\
\text { confirmed its superiority over NPH insulin }\end{array}$ \\
\hline $\begin{array}{l}\text { Cost effectiveness as add-on therapy in } \\
\text { type } 2 \text { diabetes }\end{array}$ & Clear & $\begin{array}{l}\text { The cost effectiveness of IG was superior to that of NPH insulin. It was also associated with lower } \\
\text { total costs for maintaining glycemic control than add-on therapy with rosiglitazone or pioglitazone }\end{array}$ \\
\hline
\end{tabular}




\section{Scope, aims, and objectives}

Insulin replacement therapy has been a mainstay of treatment for patients with type 1 diabetes and a third-line alternative in patients with type 2 disease unresponsive to diet/exercise and oral antidiabetic drugs. However, traditional insulin products and more recently introduced intermediate and longer-acting preparations have not provided consistent metabolic control over a 24-hour period, while at the same time avoiding the risk of hypoglycemia (which is a significant cause of morbidity, particularly at night). The introduction of longer-acting insulin analogs that more closely mimic endogenous basal insulin patterns has been facilitated by recombinant DNA technology. In combination with the development of rapid-acting analogs that can provide mealtime cover, the newer insulin products permit greater flexibility with regards to treatment regimens and the potential to more closely mimic endogenous insulin release/blood levels (Owens et al. 2000; Gummerson 2006). Insulin glargine (21A-Gly-30Ba-L-Arg-30Bb-L-Arg-human insulin; Lantus ${ }^{\circledR}$ ) is an analog of human insulin produced by recombinant DNA technology using a nonpathogenic strain of Escherichia coli (K12). Once-daily subcutaneous insulin glargine has a prolonged duration of action without significant peaks of activity making it an ideal candidate as a long-acting (basal) insulin (Heinemann et al. 2000; Lepore et al. 2000; Owens et al. 2000; Luzio et al. 2003). The objective of this article is to review the current evidence concerning the effectiveness of insulin glargine in the clinical management of patients with type 1 or type 2 diabetes mellitus.

\section{Methods}

PubMed (http//www.ncbi.nlm.nih.gov/entrez/query.fcgi, from 1966 to date) was searched for "insulin glargine" and "HOE 901" on November 8, 2006 and updated March 10, 2007 with the limits "English language," "randomized controlled trial," "meta analysis," "humans." In addition, relevant randomized controlled clinical trials presented at the 2006 European Association for the Study of Diabetes (EASD) meeting have been included. The resulting records were then hand searched and any that did not meet the following criteria were excluded:

- Insulin glargine versus neutral protamine hagedorn (NPH) in $\geq 100$ patients with type 1 diabetes

- Insulin glargine versus continuous insulin infusion in patients with type 1 diabetes

- Insulin glargine versus NPH in $\geq 200$ patients with type 2 diabetes

- Insulin glargine versus premixed human biphasic insulin in patients with type 2 diabetes

- Insulin glargine versus oral antidiabetic drugs in patients with type 2 diabetes

- Insulin glargine versus insulin detemir in patients with type 1 or type 2 diabetes

- Large observational studies or intensive treatment dosage titration investigations involving $>1000$ patients with type 2 diabetes.
The results of the literature search and selection are shown in Table 1.

\begin{tabular}{|lc|}
\hline Table $\mathbf{1}$ | Evidence base included in the review & \\
\hline Category & Number \\
\hline Initial search & 59 \\
records excluded & 14 \\
records included & 45 \\
Additional studies identified & 4 \\
Search update, new records & 41 \\
records excluded & 17 \\
records included & 24 \\
Level 1 clinical evidence (systematic review, meta analysis) & 1 \\
Level 2 clinical evidence (RCT) & 59 \\
Level $\geq 3$ clinical evidence & 6 \\
trials other than RCT & 6 \\
case reports & 0 \\
Economic evidence & 7 \\
Total records included & 73 \\
\hline For definition of levels of evidence, see Editorial Information on inside back cover. \\
RCT, randomized controlled trial.
\end{tabular}

\section{Disease overview}

The prevalence of diabetes mellitus has risen dramatically over the last two decades and the International Diabetes Federation (IDF) has recently estimated that there are almost 250 million people with the disease worldwide; this number is projected to exceed 380 million by the year 2025 if urgent action is not taken (IDF 2007a). Geographically there is a wide variation in the incidence of type 1 and type 2 diabetes with the latter accounting for about $85-95 \%$ of cases in developed countries and a higher proportion in developing countries. Type 2 diabetes is largely the result of poor diet, excess bodyweight, and physical inactivity. There is also an association with age (the disease was previously termed "maturity-onset diabetes"), family history, and race/ethnicity. Worryingly, there is an increasing prevalence of type 2 diabetes in children and adolescents, which is fast being recognized as a global health problem (Pinhas-Hamiel \& Zeitler 2005). Type 1 diabetes accounts for approximately $5-10 \%$ of all cases and usually starts in childhood, although onset can occur at any age. A third form of the disease is gestational diabetes, which falls outside of the scope of this review.

The burden of diabetes on healthcare systems worldwide is enormous and this is reflected in prevalence data presented by the IDF, which estimates that each year 3.8 million deaths are attributable to the disease and an even greater number of patients die from cardiovascular disease that is exacerbated by comorbid diabetes mellitus (IDF 2007a). Additional relevant and startling 
statistics presented by the IDF include: diabetes is the fourth leading cause of death worldwide; it affects about $6 \%$ of the global adult population; $50 \%$ of cases remain undiagnosed (as high as $80 \%$ in some countries); it is the most frequent comorbid condition associated with kidney failure (10-20\% of diabetics die of renal failure); and diabetic retinopathy is the leading cause of vision loss in adults aged 20-65 years.

Diabetes mellitus represents a heterogeneous group of metabolic disorders which are characterized by hyperglycemia as a result of severe insulin deficiency (type 1 diabetes) or defects in insulin resistance, impaired insulin secretion, and increased glucose production (type 2 diabetes). Several distinct forms of diabetes exist, resulting from a complex interaction of genetics, environmental factors, and lifestyle choices (Powers 2005).

Diabetes is often associated with comorbidities, such as hypertension, diabetic nephropathy, dyslipidemia, and thrombotic abnormalities such as impaired fibrinolysis and platelet hyperreactivity. When viewed as a whole they represent a milieu of risk factors that go some way to explaining why atherothrombosis (e.g. myocardial infarction, ischemic stroke) is the leading cause of mortality in patients with type 2 diabetes. They also highlight the need for a holistic approach to managing such patients with major goals that include establishing tight metabolic control, normalization of blood pressure and lipid levels, preservation of renal function, improvement of fibrinolytic activity, and cessation of smoking.

The Diabetes Control and Complications Trial Research Group (DCCT Research Group 1993) and the UK Prospective Diabetes Study (UKPDS 1998a,b) provide convincing evidence that tight and sustained management of glycemia $\left(\mathrm{HbA}_{1 \mathrm{c}}\right.$ to $\left.\leq 7 \%\right)$, using an intensive therapy regimen and regular follow-up/monitoring, reduces both the development and progression of microvascular complications. In the DCCT trial, for example, intensive therapy reduced microalbuminuria by $39 \%$, albuminuria by $54 \%$, and clinical neuropathy by $60 \%$. The drawback was an increased incidence of hypoglycemia which is the single biggest barrier to administering higher dosages of insulin. Longer-term follow-up of $93 \%$ of patients included in the DCCT trial over a period of 17 years showed that intensive therapy reduced the risk of any cardiovascular disease events by $42 \%(P=0.02)$ and the risk of nonfatal myocardial infarction, stroke, or death from cardiovascular disease by $57 \%(P=0.02)$ (Nathan et al. 2005).

\section{Current therapy options}

The major aims of treatment for patients with type 1 or type 2 diabetes mellitus are to provide a level of glycemic control similar to that of nondiabetic individuals, to eliminate or delay the development of microvascular/macrovascular complications, and to minimize debilitating episodes of hypoglycemia and thus improve quality of life (QOL). Most treatment guidelines are now built upon the premise that tight management of blood glucose levels is pivotal to achieve optimal patient care (Powers 2005; IDF 2007b). As noted previously, however, management of the diabetic patient is not simply a matter of treating the metabolic abnormality, and a holistic approach is required to minimize cardiovascular risk, diabetic nephropathy, and diabetic retinopathy. Irrespective of the type of diabetes it is important that management programs are individualized, taking into account patient characteristics and needs, as well as medical, social, nutritional, and lifestyle issues. For patients with type 1 diabetes mellitus (and therefore minimal or zero endogenous insulin secretory capacity), replacement insulin is a prerequisite for survival. Ideally, the replacement regimen should mimic a "normal" 24-hour insulin profile. In type 2 diabetes, diet, exercise, and oral antidiabetic drugs are the cornerstone of treatment. However, if glycemic control cannot be achieved using these measures, then insulin therapy should be considered, either in addition to, or in place of, oral antidiabetic drugs.

Traditional insulin products have generally proven to be suboptimal with regards to providing a consistent level of hormone for maintaining metabolic balance over a 24-hour period, while at the same time limiting the development of adverse effects such as hypoglycemia. Intermediate and longeracting preparations have been developed allowing less-frequent administration through complexing with zinc (lente and ultralente insulin) or protamine (NPH) which helps delay the absorption of insulin. However, these products still have pronounced peaks following subcutaneous injection and may be associated with episodes of hypoglycemia. Furthermore, their duration of action may be too short to allow full 24-hour cover with once-daily administration. The introduction of longer-acting insulin analogs which more closely mimic endogenous basal insulin patterns has

Table 2 | Commonly used human and analog insulins (adapted from Profit 2005; Gummerson 2006; ADA 2007)

\begin{tabular}{|c|c|c|}
\hline Generic name & Brand name & Form \\
\hline Rapid-acting & Onset: within 15 mins & Duration: up to $4 \mathrm{~h}$ \\
\hline Insulin aspart & Novolog, NovoRapid & Analog \\
\hline Insulin glulisine & Apidra & Analog \\
\hline Insulin lispro & Humalog & Analog \\
\hline Short-acting & Onset: within $1 \mathrm{~h}$ & Duration: up to $18 \mathrm{~h}$ \\
\hline Regular human insulin & Humulin R, Novolin R & Human \\
\hline Biphasic insulin analogs & Onset: $5-45 \mathrm{~min}$ & Duration: 10-16 h \\
\hline $\begin{array}{l}\text { Insulin lispro } 25 \% \text { /insulin } \\
\text { lispro protamine } 75 \%\end{array}$ & HumalogMix 25 & Analog \\
\hline $\begin{array}{l}\text { Insulin lispro } 50 \% \text { /insulin } \\
\text { lispro protamine } 50 \%\end{array}$ & HumalogMix 50 & Analog \\
\hline $\begin{array}{l}\text { Insulin aspart } 30 \% / \text { insulin } \\
\text { aspart protamine } 70 \%\end{array}$ & NovoMix 30 & Analog \\
\hline Intermediate-acting & Onset: $2-4$ h & Duration: 10-16 h \\
\hline Human NPH insulin & Humulin N, Novolin N & Human \\
\hline Long-acting & Onset: $2-4$ h & Duration: up to $24 \mathrm{~h}$ \\
\hline Insulin detemir & Levemir & Analog \\
\hline Insulin glargine & Lantus & Analog \\
\hline
\end{tabular}


been facilitated by recombinant DNA technology. In combination with the development of rapid-acting analogs which can be used to provide mealtime cover, the newer insulin products permit greater flexibility regarding treatment regimens and the potential to more closely mimic endogenous insulin release/blood levels (Owens et al. 2000; Gummerson 2006). Several types of human insulin and insulin analogs with different onsets and durations of activity are currently available (Table 2 ).

\section{Clinical efficacy of insulin glargine}

Clinical trials with insulin glargine in patients with diabetes mellitus should be assessed against the current background of inadequate glycemic control, especially in patients with type 2 disease (AACE 2007). In particular what is the level of evidence for:

- adequate glycemic control both short- and long-term

- prevention of acute episodes of hyperglycemia and hypoglycemia

- tolerability, treatment tolerance, and impact on QOL

- longer-term reduction of microvascular and macrovascular complications; improvement in QOL and survival.
The clinical efficacy of insulin glargine administered subcutaneously once daily has been extensively investigated in patients with type 1 and type 2 diabetes mellitus treated for periods of up to 40 months. There is now available a wealth of data from large well-controlled (randomized, multicenter, parallelgroup) clinical trials assessing the efficacy and tolerability of insulin glargine. Most studies evaluated its utility in basal/bolus regimens and in many trials it was compared with NPH insulin, the most widely used replacement for basal insulin. It should be noted that a drawback of a majority of these studies is that they were of open-label design; mainly as a consequence of the different appearance of the insulin preparations (insulin glargine is presented as a clear solution and $\mathrm{NPH}$ insulin as a turbid suspension). Clinical endpoints in the majority of trials were indicators of glycemic control such as fasting blood glucose (FBG), fasting plasma glucose (FPG), glycosylated hemoglobin $\left(\mathrm{HbA}_{1 \mathrm{c}}\right)$, and diurnal glucose response, and tolerability (especially hypoglycemia). A growing number of trials have taken a more holistic view and measured patient satisfaction, wellbeing, QOL, and other factors impacting overall health benefit (includingseveral economic analyses). The results of pivotal clinical trials published to date are presented in Tables 3-7.

Table 3 | Level 2 evidence of glycemic control in patients with type 1 diabetes mellitus treated with once-daily insulin glargine or once- or twice-daily NPH insulin as part of a basal/bolus regimen. All studies were open-label, randomized, multicenter, and included $>100$ patients per treatment group

\begin{tabular}{|c|c|c|c|c|c|c|c|c|c|}
\hline \multirow[t]{2}{*}{ Study } & \multirow[t]{2}{*}{ Treatment } & \multirow[t]{2}{*}{$\begin{array}{l}\text { Study } \\
\text { duration }\end{array}$} & \multicolumn{3}{|c|}{ Change from baseline to endpoint } & \multirow[t]{2}{*}{ Insulin dose } & \multicolumn{3}{|c|}{$\begin{array}{l}\text { Frequency of hypoglycemia } \\
\text { (\% patients) }\end{array}$} \\
\hline & & & $\begin{array}{l}\text { FBG } \\
\text { (mmol/L) }\end{array}$ & $\begin{array}{l}\mathrm{FPG} \\
\text { (mmol/L) }\end{array}$ & $\begin{array}{l}\mathrm{HbA}_{1 \mathrm{c}} \\
(\%)\end{array}$ & & Symptomatic & Nocturnal & Severe \\
\hline \multicolumn{10}{|c|}{ Studies in adults } \\
\hline \multirow{3}{*}{$\begin{array}{l}\text { Raskin et al. } \\
2000\end{array}$} & IG once daily $(n=310)$ & 16 weeks & -1.7 & -2.2 & -0.1 & $-4.5 U^{\mathrm{a}} ;+1.5 \mathrm{U}^{\mathrm{b}}$ & 90.6 & 69.0 & 6.5 \\
\hline & \multirow{2}{*}{$\begin{array}{l}\text { NPH once or twice } \\
\text { daily }(n=309)\end{array}$} & & -0.6 & -0.7 & -0.1 & $+0.9 U^{a} ;-0.5 U^{b}$ & 90.6 & 63.1 & 5.2 \\
\hline & & & $P=0.0001$ & $P=0.0001$ & $P=\mathrm{NS}$ & $P=\mathrm{NS}$ & $P=\mathrm{NS}$ & $P=\mathrm{NS}$ & $P=\mathrm{NS}$ \\
\hline \multirow{3}{*}{$\begin{array}{l}\text { Ratner et al. } \\
2000\end{array}$} & IG once daily (n=264) & 28 weeks & -1.12 & -1.67 & -0.16 & $-5 U^{\mathrm{a}} ;+3.9 \mathrm{U}^{\mathrm{b}}$ & 39.9 & 18.2 & 1.9 \\
\hline & \multirow{2}{*}{$\begin{array}{l}\text { NPH once or twice } \\
\text { daily }(n=270)\end{array}$} & & -0.94 & -0.33 & -0.21 & $+1.8 \mathrm{Ua}^{\mathrm{a}} ;+1.7 \mathrm{U}^{\mathrm{b}}$ & 49.2 & 27.1 & 5.6 \\
\hline & & & $P=\mathrm{NS}$ & $P=0.01$ & $P=\mathrm{NS}$ & & $P<0.05$ & $P<0.05$ & $P=N S$ \\
\hline \multirow{3}{*}{$\begin{array}{l}\text { Hershon et } \\
\text { al. } 2004\end{array}$} & IG once daily ( $n=195)$ & 28 weeks & -1.17 & ND & -0.09 & $-7.1 \mathrm{Ua}^{\mathrm{a}} ;+6.1 \mathrm{Ub}$ & 73.3 & 71.2 & 2.6 \\
\hline & \multirow{2}{*}{$\begin{array}{l}\text { NPH twice daily } \\
(n=199)\end{array}$} & & -0.56 & ND & -0.19 & $-2.3 U^{a} ;+1.0 \cup b$ & 81.7 & 69.5 & 5.1 \\
\hline & & & $P=0.02$ & & $P=\mathrm{NS}$ & & $P=0.02$ & $P=\mathrm{NS}$ & $P=\mathrm{NS}$ \\
\hline \multirow{3}{*}{$\begin{array}{l}\text { Home et al. } \\
2005\end{array}$} & IG once daily (n=292) & 28 weeks & -1.17 & -0.82 & 0.21 & $-2.0 U^{c}$ & 89.0 & 61.0 & 10.6 \\
\hline & \multirow{2}{*}{$\begin{array}{l}\text { NPH once or twice } \\
\text { daily }(n=293)\end{array}$} & & -0.89 & -0.79 & 0.10 & 0 & 84.6 & 61.1 & 15.0 \\
\hline & & & $P=\mathrm{NS}$ & $P=\mathrm{NS}$ & $P=\mathrm{NS}$ & $P=\mathrm{NS}$ & $P=\mathrm{NS}$ & $P=\mathrm{NS}$ & $P=\mathrm{NS}$ \\
\hline \multicolumn{10}{|c|}{ Study in children } \\
\hline \multirow{3}{*}{$\begin{array}{l}\text { Schober et } \\
\text { al. } 2002\end{array}$} & IG once daily ( $n=174)$ & 28 weeks & -1.29 & ND & 0.28 & $-1.3 U^{a}$ & 79.3 & 48 & 23.0 \\
\hline & \multirow{2}{*}{$\begin{array}{l}\text { NPH once or twice } \\
\text { daily }(n=175)\end{array}$} & & -0.68 & ND & 0.27 & $+2.4 U^{a}$ & 78.9 & 52 & 28.6 \\
\hline & & & $P=0.02$ & & $P=\mathrm{NS}$ & & $P=\mathrm{NS}$ & $P=\mathrm{NS}$ & $P=\mathrm{NS}$ \\
\hline
\end{tabular}




\section{Clinical evidence with insulin glargine in type 1} diabetes mellitus

Patients with type 1 diabetes require replacement insulin for survival and the current treatment regimen of choice is the basal/bolus approach, whereby a basal insulin is administered to provide 24-hour cover and supplementary rapid/short-acting insulin analogs are given at meal times to mimic physiologic prandial insulin release. The introduction of rapid-acting insulin analogs, such as insulin aspart, insulin glulisine, and insulin lispro, has greatly assisted the basal/bolus management approach and this has increased the need for an improved basal insulin to provide full 24-hour cover (Hamann et al. 2003). Conventional longer-acting insulin preparations, such as NPH, have not provided consistent 24-hour cover, thus necessitating twice-daily administration in some individuals. NPH insulin also has an early peak at around 4 to 6 hours following subcutaneous injection and this can be associated with hypoglycemia, a limiting and potentially dangerous adverse effect (Home et al. 2005). Insulin glargine is a recently developed, long-acting basal insulin that has been found to have a stable absorption rate without any pronounced peaks in plasma concentration, thereby providing near 24-hour cover (Heinemann et al. 2000; Lepore et al. 2000; Owens et al. 2000; Scholtz et al. 2005) (Fig. 1).

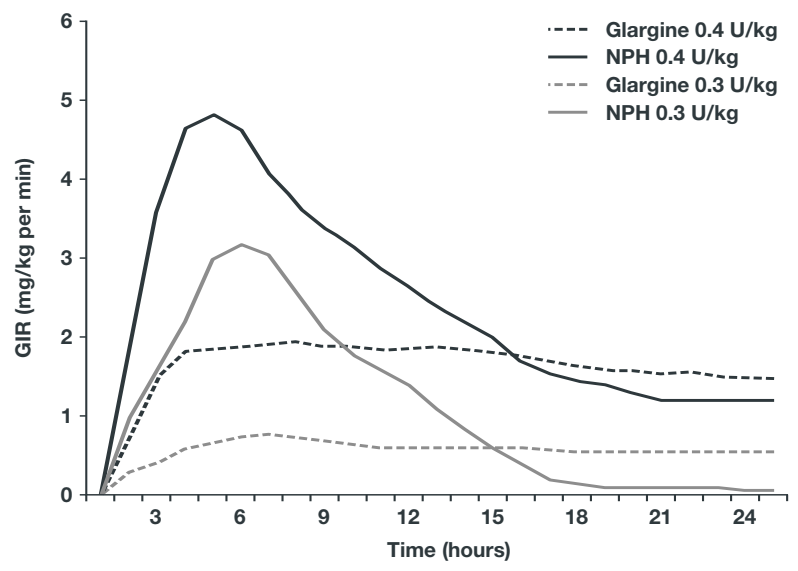

Fig. 1 | Diagramatic representation of the glycodynamic activity profile of insulin glargine and NPH insulin (as determined by GIR, based on results from euglycemic clamp studies) after administration of $0.4 \mathrm{U} / \mathrm{kg}$ to healthy volunteers (Heinemann et al. 2000) and $0.3 \mathrm{U} / \mathrm{kg}$ to patients with type 1 diabetes (Lepore et al. 2000). GIR, glucose infusion rate; $\mathrm{NPH}$, neutral protamine hagedorn.

In two of the earliest studies involving type 1 diabetes ( $n>500$ patients) previously treated with basal/bolus regimens for at least 2 months, insulin glargine (containing 30 or $80 \mathrm{mg}$ zinc) administered once daily was more effective in lowering FPG levels than NPH insulin (Pieber et al. 2000; Rosenstock et al. 2000). However, these trials were of relatively short duration (4 weeks).
Clinical evidence with insulin glargine in type 1 diabetes mellitus is based on large (>100 patients per treatment group), longerterm ( $\geq 16$ weeks), multicenter RCTs (four in adults, and one in children), providing level 2 evidence (Table 3). These studies were all open-label comparisons of once-daily insulin glargine with either once- or twice-daily NPH insulin as part of a basal/bolus regimen; the dose of basal insulin was titrated according to a target FBG level. Only outcomes related to glycemic control (including hypoglycemia) are discussed in this section; outcomes pertaining to the tolerability and safety of insulin glargine will be discussed separately.

\section{Glycemic control in adults: insulin glargine versus NPH insulin}

Raskin and colleagues (2000) compared the effects of insulin glargine once a day at bedtime and NPH insulin once or twice a day (for 16 weeks) as basal insulin treatment in patients with type 1 diabetes who were previously receiving NPH insulin for basal treatment and preprandial insulin lispro for mealtime cover. They concluded that basal insulin therapy with insulin glargine once a day appears to be as safe and at least as effective as using NPH insulin in maintaining glycemic control in patients receiving bolus insulin lispro to cover postprandial glucose surges. Insulin glargine was associated with significantly greater reductions in both FBG and FPG than NPH insulin $(P=0.0001)$. Furthermore, more patients in the insulin glargine group achieved a target FBG value of $<6.7 \mathrm{mmol} / \mathrm{L}(29.6 \%$ vs $16.8 \%$ in $\mathrm{NPH}$ insulin group). There was no difference between treatment groups with regards the occurrence of hypoglycemia.

In a 28-week study, Ratner and colleagues (2000) found that significant reductions in median FPG levels occurred with insulin glargine compared with NPH insulin and that reductions in capillary FBG levels, although comparable between the two groups at the end of the study, occurred much earlier with insulin glargine. At week 8, for example, mean FBG levels were reduced by $1.17 \mathrm{mmol} / \mathrm{L}$ in the insulin glargine group versus only $0.37 \mathrm{mmol} / \mathrm{L}$ in the NPH group $(P<0.0001)$. Importantly, insulin glargine was associated with fewer hypoglycemic episodes than $\mathrm{NPH}$ insulin. As the majority of patients with type 1 diabetes use NPH insulin twice daily, Hershon et al. (2004) conducted a subgroup analysis using only data from patients treated with oncedaily insulin glargine and twice-daily NPH insulin. The findings of this subgroup analysis support the results and conclusions from the original study. The decrease in FBG level with insulin glargine was significantly greater than with NPH insulin and, in addition, a greater percentage of patients reached a target FBG level of $<6.66$ $\mathrm{mmol} / \mathrm{L}$ (32.6\% in insulin glargine group vs $21.3 \%$ in $\mathrm{NPH}$ insulin group; $P=0.02)$. Once again, insulin glargine was associated with fewer episodes of symptomatic hypoglycemia.

Home and colleagues (2005) also found that once-daily insulin glargine produces a level of glycemic control comparable to that provided by once- or twice-daily NPH insulin, without an increased risk of hypoglycemia. However, treatment satisfaction and psychologic wellbeing were also evaluated in these patients (Witthaus et al. 2001) and showed that insulin glargine has an advantage with respect to psychologic outcomes, as 
people are apparently more satisfied with treatment with insulin glargine compared with NPH insulin. Improved patient satisfaction was recently confirmed in a 36-week crossover trial (a 4-week run-in followed by 16 weeks of each active treatment) comparing insulin glargine plus insulin aspart with NPH insulin plus insulin aspart in 60 type 1 diabetic patients (Chaterjee et al. 2007).

A number of smaller, well-controlled trials have confirmed the clinical benefits of insulin glargine. For example, Bolli and colleagues (2006) treated type 1 diabetic patients for 6 months with prandial insulin lispro plus either once-daily insulin glargine $(n=85)$ or twice-daily NPH insulin $(n=90)$. Reductions in mean daily FPG during the last month of treatment were significantly greater with insulin glargine $(-1.5 \mathrm{mmol} / \mathrm{L})$ than $\mathrm{NPH}$ insulin $(-0.5 \mathrm{mmol} / \mathrm{L}$; $P<0.05)$. Furthermore, insulin glargine was associated with less glucose variability as documented by reduced mean amplitude of glycemic excursion (MAGE) values after 6 months' treatment. In 125 patients with type 1 diabetes treated for $>1$ year and still poorly controlled $\left(\mathrm{HbA}_{1 \mathrm{c}} \geq 8 \%\right.$ ), insulin glargine subcutaneously once daily $(n=62)$ was compared with $\mathrm{NPH}$ insulin once daily $(n=63)$ as basal insulin replacement in an intensive treatment strategy (insulin lispro was given 3 times a day at mealtimes) over a period of 30 weeks. Insulin glargine was superior to NPH insulin with respect to improving $\mathrm{HbA}_{1 \mathrm{c}}$, lowering $\mathrm{FBG}$ levels, and causing a lower incidence of moderate to severe nocturnal hypoglycemia (Fulcher et al. 2005). Garg and colleagues (2005) compared basal/bolus regimens involving insulin glargine/insulin glulisine (premeal), insulin glargine/insulin glulisine (postmeal), and premeal regular human insulin in 860 patients with type 1 diabetes treated for 12 weeks. The premeal glulisine regimen resulted in lower $\mathrm{HbA}_{1 \mathrm{c}}$ levels and better postprandial glucose levels than those recorded for regular human insulin. The authors concluded that bolus insulins, such as glulisine, have more appropriate time-action profiles than regular human insulin and, in combination with newer insulin analogs such as basal insulin glargine, they may provide a more physiologic and convenient basal/bolus regimen.

Subcutaneous insulin glargine administered once daily at dinnertime has been compared with $\mathrm{NPH}$ insulin administered four times daily as part of intensive insulin regimens in studies of 3 months' (Rossetti et al. 2003) and 12 months' (Porcellati et al. 2004) duration. Both trials noted advantages for insulin glargine over NPH insulin in terms of lower daily blood glucose levels, the proportion of patients achieving blood glucose target during the day, reduction in $\mathrm{HbA}_{1 \mathrm{c}}$, a lower incidence of hypoglycemia, and simpler dosage schedule.

The reviewed studies provide a body of evidence highlighting the efficacy (and tolerability in terms of hypoglycemia) of insulin glargine administered subcutaneously once daily to patients with type 1 diabetes mellitus. Overall, it has been shown to be at least as effective as NPH insulin administered either once or twice daily as part of a basal/bolus treatment strategy. Indeed, this evidence was reviewed by the National Institute for Health and Clinical Excellence (NICE 2002), which approved its use in patients with type 1 diabetes.
Glycemic control in adults: insulin glargine versus other antidiabetic treatments

Pieber and colleagues (2007) compared twice-daily insulin detemir $(n=161)$ and once-daily insulin glargine $(n=159)$, both in combination with bolus insulin aspart, in patients with type 1 diabetes. Glycemic control was similar for the two treatments with the exceptions that insulin glargine produced a significantly lower FPG level (7.0 vs $7.7 \mathrm{mmol} / \mathrm{L} ; P<0.001)$ and insulin detemir a significantly lower predinner plasma glucose concentration $(P<0.05)$. The overall risk of hypoglycemia was also comparable for the two basal insulin therapies, although detemir was associated with significantly fewer severe (73\%) and nocturnal (32\%) episodes. Changes in bodyweight were not significantly different between the two groups in this 26-week trial. Both basal insulin dosage and total daily insulin dosage were higher in the insulin detemir group $(0.47 / 0.83$ vs $0.35 / 0.74 \mathrm{U} / \mathrm{kg}$, respectively). Contrasting results come from an observational study recently published by Currie and colleagues (2007). A total of 2808 patients treated with insulin glargine and 333 patients treated with insulin detemir were sourced from The Health Improvement Network (THIN) database (UK general practices) and analyzed. The results showed a trend favoring insulin glargine both in terms of glycemic control and reduced hypoglycemia.

The introduction of rapid-acting insulin analogs has aided the development of intensified insulin regimens which are designed to maintain tight glycemic control, and thus reduce longer-term complications associated with type 1 diabetes. This intensified basal/bolus approach to diabetes management is best achieved with either a continuous subcutaneous insulin infusion or multiple daily administration of NPH insulin, augmented with a rapid-acting insulin to provide mealtime cover (Rosetti et al. 2003). The introduction of insulin glargine provides an alternative basal insulin strategy given its 24-hour profile with no distinct peaks in activity, and two recent small studies have compared basal therapy with insulin glargine with that of continuous subcutaneous infusion in patients with type 1 diabetes.

In a crossover trial of short duration (5 weeks per treatment) continuous subcutaneous insulin aspart infusion resulted in lower glycemic exposure without an increased risk of hypoglycemia, as compared with multiple daily injections of insulin aspart/insulin glargine (Hirsch et al. 2005). The authors noted that for patients receiving continuous infusion therapy, multiple injections with insulin aspart/insulin glargine is a viable option for periods when the pump cannot be used (for example because of a pump malfunction, skin problems, physical activity, etc). A similar conclusion was reached by Bode and colleagues (2005) in a study involving 38 patients with type 1 diabetes who switched from continuous subcutaneous infusion with insulin lispro to multiple daily injections with insulin glargine and insulin lispro. In this trial, insulin glargine was administered at a dosage equal to (1:1) or 1.2 times (1:1.2) the mean total daily continuous subcutaneous infusion basal insulin dose, and the former (1:1) was recommended as the preferred choice for pump-free periods since it provided effective glycemic control and a lower propensity for causing hypoglycemia. 
Studies assessing insulin glargine administration regimens

A number of studies have assessed issues relating to timing of administration, titration, and dosage. The AT.LANTUS Study Group reported that in a large population of patients with long-standing, suboptimally controlled, type 1 diabetes $(n=2442)$, two insulin glargine regimens (insulin glargine increased in increments of at least $10 \%$, but not $>4 \mathrm{U}$; or insulin glargine increased in increments of 1-6 U) produced equivalent statistically significant improvements in glycemic control with low rates of severe hypoglycemia (Gomis et al. 2007). In terms of timing of administration, Hamann et al. (2003) reported no clinically relevant differences in efficacy or safety with insulin glargine administered before breakfast, before dinner, or at bedtime. Likewise, Grimaldi and colleagues (2007) observed no clinically relevant differences in efficacy or tolerability in type 1 diabetic patients administered insulin glargine at dinnertime $(n=589)$ or bedtime $(n=589)$ for 26 weeks.

Some clinicians have observed predinner increases in blood glucose levels when insulin glargine is injected at bedtime, and Ashwell and colleagues (2006a) have suggested that it may be better to administer insulin glargine at lunchtime or dinnertime to avoid this effect. The same group (Ashwell et al. 2006b) assessed once (dinnertime) and twice (half doses administered at breakfast and dinnertime) daily administration of insulin glargine in a crossover study involving 20 patients with type 1 diabetes treated for 4 weeks. The twice-daily regimen resulted in lower blood glucose levels after breakfast, lunch, and before dinner, and it was also associated with lower mean 24-hour blood glucose levels ( 7.1 vs $8.8 \mathrm{mmol} / L ; P=0.031$ ) and less within-day variability in blood glucose levels $(P=0.044)$. The authors concluded that for patients who experience late afternoon increases in blood glucose levels, twice-daily insulin glargine is a suitable alternative which does not require an increase in insulin dosage nor does it negatively impact treatment satisfaction.

\section{Glycemic control in children}

The principle of achieving tight metabolic control in patients with type 1 diabetes so as to delay the onset and slow the progression of both microvascular and macrovascular complications applies as much to children as it does to adults (DCCT Research Group 1994). However, adequate control is difficult in younger patients due to endocrine, behavioral, and social factors. As a result, less than one-third of children and adolescents being treated for diabetes are considered to be well controlled (Mortensen \& Hougaard 1997).

Schober and colleagues (2002) compared the efficacy of insulin glargine with NPH insulin in children and adolescents aged 5-16 years with type 1 diabetes mellitus. Although there was no difference between the insulin glargine and NPH insulin treatment groups with respect to baseline-to-endpoint change in $\mathrm{HbA}_{1 \mathrm{c}}$ levels, significant reductions in FBG levels were observed with insulin glargine $(-1.29 \mathrm{mmol} / \mathrm{L})$ compared with $\mathrm{NPH}$ insulin (-0.68 mmol/L; $P=0.02)$. In addition, a higher percentage of patients using insulin glargine $(43.9 \%)$ reached the target FBG level at endpoint compared with NPH insulin (39.0\%). The frequency of symptomatic hypoglycemia was similar between the two groups despite a nonsignificant trend to fewer episodes of severe hypoglycemia and severe nocturnal hypoglycemia in those treated with insulin glargine.

These findings are supported by a recent smaller study by Chase et al. (2006), who compared the efficacy of once-daily insulin glargine $(n=85)$ with twice-daily NPH or lente $(n=90)$ as basal therapy in pediatric patients with type 1 diabetes treated with a multiple daily injection regimen including premeal insulin lispro. Despite only a small reduction in mean $\mathrm{HbA}_{1 \mathrm{c}}$ from baseline to endpoint in both groups, they reported that in patients with a high baseline $\mathrm{HbA}_{1 \mathrm{c}}$, insulin glargine produced a significantly greater reduction in mean $\mathrm{HbA}_{1 \mathrm{c}}$ than $\mathrm{NPH} /$ lente. Patients treated with insulin glargine also showed less blood glucose variability assessed during continuous blood glucose monitoring. Rates of hypoglycemia were comparable between the two treatment groups.

A retrospective analysis of the medical records of 64 children with type 1 diabetes aged under 6 years documented a decrease in severe hypoglycemia, particularly at night, during the first 6 months of therapy with insulin glargine (Dixon et al. 2005). In the 6 months before the study period, 16 severe hypoglycemic events were observed compared with three during the first 6 months of insulin glargine therapy (12 night-time severe hypoglycemic events were noted prestudy and only one during treatment with insulin glargine). Similar results were recorded in a group of 34 preschool children (aged 2.6-6.3 years) who were treated with a flexible multiple-day insulin regimen (premeal lispro plus bedtime glargine) for at least 1 year (Alemzadeh et al. 2005). $\mathrm{HbA}_{1 \mathrm{c}}$ and the incidence of severe hypoglycemia were significantly reduced compared with previous treatment (premeal lispro plus twice-daily ultralente) and the best results were achieved in children with normal bodyweight. Given the adverse impact severe hypoglycemia may have on the developing brain in young children, the authors recommend that further controlled studies should be undertaken to confirm these clinically important findings.

Another retrospective case analysis assessed the effectiveness of insulin glargine in patients under 21 years (range 2-20 years) with considerably higher mean $\mathrm{HbA}_{1 \mathrm{c}}$ levels at baseline $(9.7 \pm 1.9 \%)$ despite previously receiving NPH insulin (Hathout et al. 2003). The majority of patients had type 1 diabetes and $\mathrm{HbA}_{1 \mathrm{c}}$ was significantly decreased from a baseline of $9.5 \%$ to $8.6 \%(P<0.001)$ following 9 months' treatment with insulin glargine. This reduction was associated with a significant decrease in hypoglycemia (12.2\% to $10.7 \% ; P=0.004)$, but surprisingly little change in mean blood glucose levels. Colino et al. (2005) also documented a significant reduction in $\mathrm{HbA}_{1 \mathrm{c}}$ levels following 6 months' therapy in 80 patients aged 2 to 19 years with type 1 diabetes treated with insulin glargine plus short-acting (regular human) insulin or a rapidacting analog to provide mealtime cover. $\mathrm{HbA}_{1 \mathrm{c}}$ fell from $7.63 \%$ to $7.14 \% \quad(P<0.001)$ in the total cohort and this reduction was associated with decreased FBG (161 to $150 \mathrm{mg} / \mathrm{dL} ; P=0.05)$ and a lower incidence of severe hypoglycemia (0.18 to 0.11 events/patient; not significant). In a study of shorter duration (16 weeks), Doyle and colleagues (2004) reported a significantly 
$(P<0.05)$ greater reduction in $\mathrm{HbA}_{1 \mathrm{c}}$ levels following continuous subcutaneous insulin infusion $(8.1 \%$ to $7.2 \%)$ compared with a multiple daily injection regimen including insulin glargine $(8.2 \%$ to $8.1 \%)$ in 32 young patients (8-21 years) with type 1 diabetes treated for 16 weeks. However, in a similarly designed study involving 32 type 1 diabetic children (mean age 12.5 years) treated for 2 years with continuous subcutaneous insulin infusion or a multiple daily injection regimen including insulin glargine, the two treatment approaches were found to be equally effective and well tolerated (GarciaGarcia et al. 2007).

\section{Insulin dosage}

In all five of the studies summarized in Table 3, the daily basal insulin dose tended to increase from baseline to endpoint for those patients in the NPH insulin treatment group. In comparison, there was a decrease in those receiving insulin glargine and this was almost entirely due to a reduction in the daily basal insulin dose seen in those patients previously using a twice-daily NPH insulin regimen. This fall in daily basal insulin dose was associated with a small increase in total daily bolus dosage (short- or rapid-acting insulins). It has been suggested that this need for less basal insulin when using insulin glargine, along with the lower FBG levels it results in, may allow for more aggressive bolus therapy with fast-acting insulins, and this may further help improve glycemic control in patients with type 1 diabetes (Hershon et al. 2004).

\section{Clinical evidence with insulin glargine in adults with type 2 diabetes mellitus}

Insulin therapy in patients with type 2 diabetes mellitus is generally reserved for patients unresponsive to management with diet, exercise, and oral antidiabetic drugs. This is reflected in clinical trials involving insulin glargine since inclusion criteria usually specified patients with type 2 diabetes who did not achieve good metabolic control (usually $\mathrm{HbA}_{1 \mathrm{c}}>7-7.5 \%$ ) despite being treated with one or more oral antidiabetic agents. Clinical assessment of insulin glargine in patients with type 2 diabetes has included the following:

- Large RCTs (level 2 evidence) and a meta analysis (level 1 evidence) versus NPH insulin

- Seven RCTs against premixed biphasic insulins (level 2 evidence)

- Two randomized clinical trials with exenatide (level 2 evidence)

- Randomized clinical trials versus rosiglitazone $(n=4)$ and pioglitazone $(n=1)$ (both level 2 evidence)

- A large observational study from everyday practice in Germany involving >12 000 patients (level 4 evidence)

- Two large randomized controlled "treatment approach" clinical trials (level 2 evidence) assessing different treatment algorithms.
Glycemic control in adults: insulin glargine versus NPH insulin

The emphasis in this section of the review is given to randomized, controlled clinical trials which compared insulin glargine with NPH insulin and included $>200$ patients with type 2 diabetes per treatment group (Table 4). All studies included insulin-naïve patients except the studies of Rosenstock et al. (2001) and Massi Benedetti et al. (2003); the latter is a follow-up of the study reported by Yki-Järvinen et al. (2000), but includes data from an additional 144 patients who had previously received insulin therapy.

The results from six of these large controlled trials (level 2 evidence) comparing subcutaneous insulin glargine with subcutaneous NPH insulin show that over a period of up to 1 year, both insulin glargine and NPH insulin produced clinically significant improvements in glycemic control with some trials reporting high response rates. For example Riddle and colleagues (2003) noted that the majority of patients ( $60 \%)$ attained an $\mathrm{HbA}_{1 \mathrm{c}}$ level of $7 \%$ or less with both insulin glargine and NPH insulin. Similarly Eliaschewitz et al. (2006) reported that approximately $50 \%$ of patients achieved an $\mathrm{HbA}_{1 \mathrm{c}}$ level of $<7.5 \%$. Pan and colleagues (2007) observed a lower overall response rate in terms of $\mathrm{HbA}_{1 \mathrm{c}}(<7.5 \%)$ in Asian patients treated with insulin glargine (38.1\%) or NPH insulin (30.3\%). However, a greater percentage of patients $(62.3 \%$ and $58.7 \%$, respectively) achieved a target FBG level of $\leq 120 \mathrm{mg} / \mathrm{dL}$.

Interestingly, Fritsche et al. (2003) found that insulin glargine and $\mathrm{NPH}$ insulin administered at bedtime reduced $\mathrm{HbA}_{1 \mathrm{c}}$ to below $7.5 \%$ in approximately one-third of patients, but a significantly greater number of patients responded when insulin glargine was administered before breakfast (43\%). In this study $\mathrm{HbA}_{1 \mathrm{c}}$ levels improved by a statistically greater extent with morning insulin glargine $(-1.24)$ than with either NPH insulin $(-0.84 ; P<0.001)$ or bedtime insulin glargine $(-0.96 ; P=0.008)$. Insulin glargine administered before breakfast resulted in a greater decrease in mean daily blood glucose levels (determined during diurnal blood glucose testing) compared with both bedtime NPH $(P<0.001)$ and bedtime insulin glargine $(P=0.002)$. Yki-Järvinen et al. (2000) reported a significantly greater decrease in blood glucose concentrations before and after dinner in patients treated with insulin glargine compared with those treated with $\mathrm{NPH}$ insulin (both drugs administered at bedtime). Similarly, Pan et al. (2007) observed lower glucose levels postdinner in the insulin glargine group (236 vs $249 \mathrm{mg} / \mathrm{dL} ; P<0.05$ ), and also a decrease in mean daily blood glucose levels $(-94 \mathrm{vs}-80 \mathrm{mg} / \mathrm{dL}$; $P=0.018)$.

A consistent and important clinical finding in all of these large trials was that insulin glargine resulted in a lower incidence of nocturnal hypoglycemia than that associated with NPH insulin. The authors of all these large randomized clinical trials concluded that, compared with NPH insulin, once-daily insulin glargine produced equivalent glycemic control (in two studies there were some significant changes favoring insulin glargine), but the newer insulin analog had the significant clinical advantage of causing less nocturnal hypoglycemia-a frequent 
Table 4 | Level 2 evidence of glycemic control in patients with type 2 diabetes mellitus treated with once-daily insulin glargine or once- or twice-daily NPH insulin in combination with oral antidiabetic drugs (except for Rosenstock et al. 2001, in which regular human insulin premeals was maintained). All studies were randomized, multicenter, of open-label design, and included $>200$ patients per treatment group

\begin{tabular}{|c|c|c|c|c|c|c|c|c|c|}
\hline \multirow[t]{2}{*}{ Study } & \multirow[t]{2}{*}{ Treatment } & \multirow{2}{*}{$\begin{array}{l}\text { Study } \\
\text { duration }\end{array}$} & \multicolumn{3}{|c|}{ Change from baseline to endpoint } & \multirow[t]{2}{*}{ Insulin dose } & \multicolumn{3}{|c|}{ Frequency of hypoglycemia ( $\%$ patients) } \\
\hline & & & $\begin{array}{l}\text { FBG } \\
\text { (mmol/L) }\end{array}$ & $\begin{array}{l}\text { FPG } \\
\text { (mmol/L) }\end{array}$ & $\mathrm{HbA}_{1 \mathrm{c}}(\%)$ & & Symptomatic & Nocturnal & Severe \\
\hline \multirow{3}{*}{$\begin{array}{l}\text { Riddle et al. } \\
2003\end{array}$} & IG o.n. $(n=367)$ & \multirow[t]{3}{*}{24 weeks } & ND & -4.5 & -1.65 & $47.2 \mathrm{U}$ & $13.9^{\mathrm{a}}$ & $4.0^{\mathrm{a}}$ & 2.5 \\
\hline & \multirow[t]{2}{*}{ NPH o.n. $(n=389)$} & & ND & -4.1 & -1.59 & $41.8 \mathrm{U}$ & $17.7^{\mathrm{a}}$ & $6.9^{\mathrm{a}}$ & 1.8 \\
\hline & & & & $P=\mathrm{NS}$ & $P=\mathrm{NS}$ & $P=0.005$ & $P<0.02$ & $P<0.001$ & $P=\mathrm{NS}$ \\
\hline \multirow{3}{*}{$\begin{array}{l}\text { Rosenstock } \\
\text { et al. } 2001\end{array}$} & IG o.n. $(n=259)$ & \multirow[t]{3}{*}{28 weeks } & $-1.3^{\mathrm{b}}$ & ND & -0.41 & $0.75 \mathrm{U} / \mathrm{kg}^{\mathrm{c}}$ & 61.4 & 31.3 & ND \\
\hline & \multirow{2}{*}{$\begin{array}{l}\text { NPH o.n., or o.n. } \\
\text { and o.m. }(n=259)\end{array}$} & & $-1.2^{\mathrm{b}}$ & ND & -0.59 & $0.75 \mathrm{U} / \mathrm{kg}^{\mathrm{c}}$ & 66.8 & 40.2 & ND \\
\hline & & & $P=\mathrm{NS}$ & & $P=\mathrm{NS}$ & $P=\mathrm{NS}$ & $P<0.05$ & $P<0.02$ & \\
\hline \multirow{3}{*}{$\begin{array}{l}\text { Eliaschewitz } \\
\text { et al. } 2006\end{array}$} & IG once daily $(n=231)$ & \multirow[t]{3}{*}{24 weeks } & -4.8 & ND & -1.38 & $32.6 \mathrm{U}$ & 52.8 & 20.4 & 2.6 \\
\hline & \multirow{2}{*}{$\begin{array}{l}\text { NPH once daily } \\
(n=250)\end{array}$} & & -4.1 & ND & -1.44 & $31.2 \mathrm{U}$ & 62.8 & 34.8 & 4.4 \\
\hline & & & $P=\mathrm{NS}$ & & $P=\mathrm{NS}$ & $P=\mathrm{NS}$ & $P=0.042$ & $P<0.001$ & $P=0.303$ \\
\hline \multirow{4}{*}{$\begin{array}{l}\text { Fritsche et al. } \\
2003\end{array}$} & IG o.m. (n=236) & \multirow[t]{4}{*}{28 weeks } & -5.1 & ND & $-1.24^{d}$ & $40 \mathrm{U}$ & 56 & $17^{f}$ & 2.1 \\
\hline & IG o.n. $(n=227)$ & & -5.2 & ND & -0.96 & $37 \mathrm{U}$ & $43^{e}$ & $23^{f}$ & 1.8 \\
\hline & \multirow[t]{2}{*}{ NPH o.n. $(n=293)$} & & -5.3 & ND & -0.84 & $39 \mathrm{U}$ & 58 & 38 & 2.6 \\
\hline & & & $P=\mathrm{NS}$ & & & $P=\mathrm{NS}$ & & $P<0.001$ & $P>0.2$ \\
\hline \multirow{3}{*}{$\begin{array}{l}\text { Yki-Järvinen } \\
\text { et al. } 2000\end{array}$} & IG o.n. $(n=214)$ & \multirow[t]{3}{*}{52 weeks } & $\mathrm{ND}^{\mathrm{g}}$ & ND & -0.76 & $23 \mathrm{U}$ & $33^{b}$ & 9.9 & 0 \\
\hline & \multirow[t]{2}{*}{ NPH o.n. $(n=208)$} & & $\mathrm{ND}^{\mathrm{g}}$ & ND & -0.66 & $21 \mathrm{U}$ & $42^{b}$ & 24 & 0 \\
\hline & & & & & $P=\mathrm{NS}$ & & $P=0.04$ & $P<0.001$ & $P=\mathrm{NS}$ \\
\hline \multirow{3}{*}{$\begin{array}{l}\text { Massi } \\
\text { Benedetti et } \\
\text { al. } 2003\end{array}$} & IG o.n. $(n=289)$ & \multirow[t]{3}{*}{52 weeks } & -2.7 & -2.8 & -0.46 & ND & 32.5 & 9.5 & 1.7 \\
\hline & \multirow[t]{2}{*}{$\mathrm{NPH}$ o.n. $(n=281)$} & & -2.6 & -2.7 & -0.38 & ND & 37.3 & 22.2 & 1.1 \\
\hline & & & $P=0.26$ & $P=0.65$ & $P=0.415$ & & $P=\mathrm{NS}$ & $P=0.0006$ & $P=\mathrm{NS}$ \\
\hline \multirow{3}{*}{$\begin{array}{l}\text { Pan et al. } \\
2007\end{array}$} & IG o.n. $(n=220)$ & 24 weeks & -5.8 & ND & -0.99 & $22 \mathrm{U}$ & $515^{\mathrm{h}}$ & $221^{\mathrm{h}}$ & $5^{\mathrm{h}}$ \\
\hline & \multirow[t]{2}{*}{ NPH o.n. $(n=223)$} & & -5.7 & ND & -0.77 & $23 U$ & $908^{\mathrm{h}}$ & $620^{h}$ & $28^{h}$ \\
\hline & & & $P=\mathrm{NS}$ & & $P=0.032$ & $P=\mathrm{NS}$ & $P=0.0003$ & $P=0.001$ & $P<0.03$ \\
\hline
\end{tabular}

barrier to starting insulin therapy in patients with type 2 diabetes mellitus.

These findings have been augmented by a meta analysis (level 1 evidence) of four of these trials (Yki-Järvinen et al. 2000/Massi Benedetti et al. 2003; Rosenstock et al. 2001; Fritsche et al 2003; Riddle et al. 2003) which is summarized in Table 5 (Rosenstock et al. 2005). In this analysis, involving $>1000$ patients per treatment group, insulin glargine and $\mathrm{NPH}$ insulin produced equivalent glycemic control as determined by the number of patients achieving $\mathrm{HbA}_{1 \mathrm{c}}$ levels $\leq 7.0 \%$, although insulin glargine was associated with significantly lower FPG levels (8 vs $9 \mathrm{mmol} / \mathrm{L} ; P=0.023)$. In line with the conclusions reached by the individual clinical trials, the main finding of clinical consequence from the meta analysis was the significantly lower risk of hypoglycemia occurring with insulin glargine. The risk reduction was $59 \%$ for severe nocturnal hypoglycemia $(P=0.0231)$, $46 \%$ for severe hypoglycemia $(P=0.0442), 26 \%$ for nocturnal hypoglycemia $(P<0.0001)$, and $11 \%$ for overall documented hypoglycemia $(P=0.0006)$.
Studies involving smaller numbers of patients have produced comparable results to the large studies described above (HOE 901/2004 Study Investigators Group 2003; Fonseca et al. 2004; Yki-Järvinen et al. 2006). Furthermore, at a titration target of FBG $\leq 5.5 \mathrm{mmol} / \mathrm{L}$, Standl et al. (2006) noted that bedtime and morning regimens of insulin glargine were equivalent in terms of achieving good glycemic control without any significant difference in hypoglycemia. In the longest study to date (an extension of the large study reported by Yki-Järvinen et al. 2000 and Massi Benedetti et al. 2003), 198 type 2 diabetic patients received subcutaneous insulin glargine for up to a further 28 months in an open noncontrolled clinical study. The longer-term efficacy (assessed by $\mathrm{HbA}_{1 \mathrm{c}}$ levels) and safety of insulin glargine was confirmed in this trial (Kacerovsky-Bielesz et al. 2006).

An interesting study reported by Gerstein and coworkers (2006) is the Canadian Insight (Implementing New Strategies with Insulin Glargine for Hyperglycemia Treatment) Study. This trial assessed the "early" introduction of insulin glargine in 405 patients with type 2 diabetes with an $\mathrm{HbA}_{1 \mathrm{c}}$ of $\geq 7.5 \%$, but not receiving full 


$\begin{aligned} & \text { Table } 5 \text { | Meta analysis of four randomized, open-label, } \\ & \text { clinical trials comparing insulin glargine ( } \mathrm{n}=1142)\end{aligned}$
$\begin{aligned} & \text { with NPH insulin ( } \mathrm{n}=1162) \text { in patients with type } 2 \\ & \text { diabetes poorly controlled by oral antidiabetic drugs }\end{aligned}$
[or receiving preprandial regular human insulin
(Rosenstock et al. 2001)] (Rosenstock et al. 2005)

$\mathrm{HbA}_{10}$, glycosylated hemoglobin; NPH, neutral protamine hagedorn; NS, nonsignificant.

doses of oral antidiabetic therapy. Two hundred and six patients were randomized to receive insulin glargine and 199 to continue usual dose titration with oral therapy (to a FPG of $\leq 5.5 \mathrm{mmol} / \mathrm{L}$ and an $\mathrm{HbA}_{1 \mathrm{c}}$ of $\leq 7 \%$ ) for a period of at least 6 months. Compared with usual therapy, patients receiving insulin glargine achieved significantly better glycemic control as evidenced by greater decreases in $\mathrm{HbA}_{1 \mathrm{c}}(-1.55$ vs $-1.25 \% ; P=0.005)$ and $\mathrm{FPG}$ (-3.89 vs $-2.31 \mathrm{mmol} / \mathrm{L} ; P=0.0001)$, and the frequency of achieving two consecutive $\mathrm{HbA}_{1 \mathrm{c}}$ measurements $\leq 6.5 \%$ (insulin glargine patients were 1.7 times more likely to reach this primary endpoint; $P=0.049$ ). Insulin glargine therapy was also associated with an improved lipid profile [decreased non-high-density lipoprotein cholesterol $(P=0.02)$ and triglycerides $(P=0.02)]$ and greater increases in treatment satisfaction $(P=0.045)$, but increased bodyweight $(+1.9 \mathrm{~kg} ; P<0.0001)$.

The above findings from well-controlled clinical trials have recently been augmented by a 20-month observational study (level 4 evidence) involving >12 000 type 2 diabetic patients poorly controlled by oral therapy from everyday practice in Germany (Schreiber \& Haak 2007). The mean $\mathrm{HbA}_{1 \mathrm{c}}$ level was $8.7 \%$ at baseline $(n=11511)$, and following the addition of insulin glargine $7.2 \%$ at 3 months $(n=11296), 7.0 \%$ at 9 months $(n=6031)$, and $7.0 \%$ at 20 months $(n=2374)$.

In the above studies, changes in bodyweight were generally similar for insulin glargine and NPH insulin with two studies reporting an advantage for glargine (Rosenstock et al. 2001;
Fonseca et al. 2004) but others noting nonsignificant reductions with NPH insulin (Fritsche et al. 2003; Riddle et al. 2003). In the large observational study reported by Schreiber and Haak (2007) body mass index decreased slightly from a mean of $29.0 \mathrm{~kg} / \mathrm{m}^{2}$ at baseline to $28.5 \mathrm{~kg} / \mathrm{m}^{2}$ after 9 months of insulin glargine treatment.

\section{Glycemic control in adults: insulin glargine versus other antidiabetic treatments}

Studies comparing once-daily insulin glargine with premixed biphasic insulins in patients with type 2 diabetes mellitus poorly controlled with oral antidiabetic drugs (and in one study plus insulin; Malone et al. 2005) generally reported improved metabolic control with all of the insulin regimens (Table 6). In terms of which regimen is best with respect to improving glycemic control the results have varied, but there is a trend toward better glycemic control, increased insulin dosage, and an increased incidence of hypoglycemia with the biphasic preparations, but this has not been the case in all studies.

For example, Janka et al. (2005) found that once-daily (morning) insulin glargine in combination with glimepiride and metformin reduced $\mathrm{FBG}$ and $\mathrm{HbA}_{1 \mathrm{c}}$ levels, and was associated with significantly lower incidence of hypoglycemia compared with human insulin (30\% regular, 70\% NPH) alone. Furthermore, these advantages were also apparent in a subgroup of 130 patients aged $\geq 65$ years (Janka et al. 2007). In contrast, in the INITIATE study, biphasic insulin aspart $30 / 70$ in combination with oral antidiabetic drugs produced a significantly greater reduction in $\mathrm{HbA}_{1} \mathrm{c}$ levels than insulin glargine once daily (at bedtime) plus oral antidiabetic drugs, but this was associated with a significantly greater increase in biphasic insulin dosage $(P<0.05)$, weight gain $(P<0.01)$, and incidence of minor hypoglycemia $(P<0.05)$ (Raskin et al. 2005). Similar findings were noted in a subpopulation of patients who were not receiving thiazolidinedione treatment in the original study (Raskin et al. 2007). Comparable results with biphasic insulin aspart 30/70 (plus metformin; $n=128$ ) versus insulin glargine (plus glimepiride; $\mathrm{n}=127$ ) were reported by Kann and colleagues (2006) in a randomized trial in which patients were treated for 26 weeks. Biphasic insulin aspart 30/70 resulted in a lower mean plasma prandial glucose increment (calculated from a 7-point plasma glucose profile), but increased minor hypoglycemia.

In two crossover trials involving relatively small numbers of patients with type 2 diabetes poorly controlled by oral antidiabetic drugs (Malone et al. 2004) or by intermediate insulin with or without oral antidiabetic drugs (Malone et al. 2005), daily insulin glargine (at bedtime) was compared with biphasic insulin lispro 25/75. The authors concluded that biphasic insulin lispro $25 / 75$ was a more effective treatment option because it resulted in a greater decrease in $\mathrm{HbA}_{1 \mathrm{c}}$ levels, a higher number of $\mathrm{HbA}_{1 \mathrm{c}}$ $\leq 7 \%$ responders, and more patients achieving morning and evening blood glucose targets. However, it should be noted that insulin glargine produced a significantly greater decrease in FBG levels, and more $\mathrm{FBG} \leq 7 \mathrm{mmol} / \mathrm{L}$ responders. Insulin dosage was not increased as much in the insulin glargine group (significantly 
so in the most recent study; Malone et al. 2005). Changes with respect to hypoglycemia favored insulin glargine in one study (Malone et al. 2004) and biphasic insulin lispro in the other (Malone et al. 2005). The same group recently reported results from a crossover trial involving 20 patients with type 2 diabetes inadequately controlled by metformin and/or a sulfonylurea who received additional treatment with biphasic insulin lispro 25/75 or insulin glargine (Roach \& Malone 2006). After 3 months' treatment, 24-hour test meal assessments demonstrated that biphasic insulin lispro 25/75 was associated with lower mean postprandial glucose and 24-hour plasma glucose, but similar FPG. It was also associated with an increase in mild hypoglycemia. Intensive treatment with biphasic insulin lispro (injecting lispro 50/50 before breakfast and lunch, and lispro $25 / 75$ before dinner) produced better overall glycemic control $\left(\mathrm{HbA}_{1 \mathrm{c}}\right.$ and postprandial blood glucose levels) than insulin glargine, but it was associated with an increased incidence of mild hypoglycemia (Jacober et al. 2006).

Recent comparative studies in patients with poorly controlled type 2 diabetes demonstrated the following results with oncedaily insulin glargine:
- Insulin glargine was as effective as twice-daily exenatide 5-10 mcg twice daily, and was associated with a significantly lower incidence of gastrointestinal side effects (Heine et al. 2005; Secnik Boye et al. 2006). In the latter study insulin glargine and exenatide demonstrated comparable improvements in treatment satisfaction.

- In four clinical trials insulin glargine and rosiglitazone produced similar levels of glycemic control in double- or triple-therapy regimens (Rosenstock et al. 2006; Triplitt et al. 2006; Reynolds et al. 2007; Vinik \& Zhang 2007). Rosenstock and colleagues (2006) reported greater reductions in $\mathrm{HbA}_{1 \mathrm{c}}$ levels in patients whose baseline value was $\geq 9.5 \%$, while Vinik and Zhang (2007) noted statistically significant improvements in QOL measures for insulin glargine compared with rosiglitazone.

- Insulin glargine improved glycemic control and diabetesrelated QOL compared with pioglitazone (Meneghini et al. 2006).

- In older patients ( $\geq 60$ years) with poorly controlled type 2 diabetes, intensive therapy with continuous subcutaneous infusion or multiple daily injections (insulin lispro/insulin glargine) resulted in an $\mathrm{HbA}_{1 \mathrm{c}}<7 \%$ response rate of approximately $80 \%$ (Herman et al. 2005).

Table 6 | Level 2 evidence of glycemic control in patients with type 2 diabetes mellitus poorly controlled on previous therapy, comparing insulin glargine and premixed biphasic insulins over a period of 16-28 weeks

\begin{tabular}{|c|c|c|c|c|c|c|c|c|}
\hline \multirow[t]{2}{*}{ Reference } & \multirow[t]{2}{*}{ Treatment } & \multicolumn{2}{|c|}{ Change from baseline } & \multirow[t]{2}{*}{ Insulin dose } & \multicolumn{2}{|l|}{ Hypoglycemia } & \multirow{2}{*}{$\begin{array}{l}\text { Pts achieving } \\
\text { blood glucose } \\
\text { target of } \\
<5.6-7.0 \\
\text { mmol/L (\%) }\end{array}$} & \multirow{2}{*}{$\begin{array}{l}\text { Pts } \\
\text { achieving } \\
\text { HbA }_{1 \mathrm{c}} \text { level } \\
<7 \%\end{array}$} \\
\hline & & $\begin{array}{l}\text { FBG } \\
(\mathrm{mmol} / \mathrm{L})\end{array}$ & $\begin{array}{l}\mathrm{HbA}_{1 \mathrm{c}} \\
(\%)\end{array}$ & & $\begin{array}{l}\text { Symptomatic } \\
\text { (\% pts) }\end{array}$ & $\begin{array}{l}\text { Nocturnal } \\
\text { (\% pts) }\end{array}$ & & \\
\hline \multirow{3}{*}{$\begin{array}{l}\text { Janka et al. } \\
2005\end{array}$} & IG once dailya $(n=177)$ & -3.1 & -1.64 & $+18.3 \cup$ & $2.62^{c}$ & $0.51^{\mathrm{c}}$ & 31.6 & 49.4 \\
\hline & Premixed human insulin 30/70 & -2.2 & -1.31 & $+43.9 \mathrm{U}$ & $5.73^{c}$ & $1.04^{c}$ & 15.0 & 31.0 \\
\hline & twice daily ${ }^{b}(n=187)$ & $P=0.0001$ & $P=0.0003$ & & $P=0.0009$ & $P=0.045$ & $P=0002$ & $P=0.06$ \\
\hline \multirow{3}{*}{$\begin{array}{l}\text { Raskin et al. } \\
2005\end{array}$} & IG once daily ${ }^{d}(n=116)$ & $125^{\mathrm{e}}$ & -2.36 & $+0.42 \mathrm{U} / \mathrm{kg}$ & $0.7^{f}$ & ND & $57^{9}$ & 40 \\
\hline & Biphasic insulin aspart 30/70 & $125^{\mathrm{e}}$ & -2.79 & $+0.68 \mathrm{U} / \mathrm{kg}$ & $3.4^{f}$ & ND & $36^{9}$ & 66 \\
\hline & twice daily ( $\mathrm{n}=117$ ) & $P=\mathrm{NS}$ & $P<0.01$ & $P<0.05$ & $P<0.05$ & & & $P<0.001$ \\
\hline \multirow[t]{2}{*}{$\begin{array}{l}\text { Kann et al. } \\
2006\end{array}$} & $\begin{array}{l}\text { IG once daily }(n=127)+ \\
\text { glimepiride }\end{array}$ & $-2.2^{h}$ & -0.2 & ND & 9.0 & ND & ND & 26.2 \\
\hline & $\begin{array}{l}\text { Biphasic insulin aspart } 30 / 70 \\
\text { twice daily }(n=128)+\text { metformin }\end{array}$ & $\begin{array}{l}-2.6^{\mathrm{h}} \\
P=0.23\end{array}$ & $\begin{array}{l}-0.5 \\
P=0.0002\end{array}$ & ND & $\begin{array}{l}20.3 \\
P=0.012\end{array}$ & ND & ND & $\begin{array}{l}33.1 \\
P=0.27\end{array}$ \\
\hline \multirow{3}{*}{$\begin{array}{l}\text { Malone et } \\
\text { al. } 2004\end{array}$} & IG once daily' $(n=53)$ & -1.61 & -0.9 & $+0.18 \mathrm{U} / \mathrm{kg}$ & $0.39^{k}$ & 12 & 65 & 18 \\
\hline & Biphasic insulin lispro $25 / 75$ & -0.75 & -1.3 & $+0.23 \mathrm{U} / \mathrm{kg}$ & $0.68^{k}$ & 11 & 45 & 42 \\
\hline & twice dailyj $(n=52)$ & $P<0.001$ & $P=0.003$ & $P=0.001$ & $P=0.041$ & $P=\mathrm{NS}$ & $P=0.019$ & $P<0.001$ \\
\hline \multirow{3}{*}{$\begin{array}{l}\text { Malone et } \\
\text { al. } 2005\end{array}$} & IG once daily' $(n=47)$ & -1.03 & -0.42 & $+0.09 \mathrm{U} / \mathrm{kg}$ & 0.44 & 0.34 & 51 & 12 \\
\hline & Biphasic insulin lispro $25 / 75$ & -0.52 & -1.00 & $+0.15 \mathrm{U} / \mathrm{kg}$ & 0.61 & 0.14 & 34 & 30 \\
\hline & twice dailyj $(n=50)$ & $P=0.007$ & $P<0.001$ & $P<0.001$ & $P=0.477$ & $P<0.002$ & $P=0.01$ & $P=0.002$ \\
\hline \multirow{3}{*}{$\begin{array}{l}\text { Jacober et } \\
\text { al. } 2006\end{array}$} & IG once daily ${ }^{d}(n=60)$ & ND & -0.75 & & 2.57 & 0.80 & ND & 31 \\
\hline & Biphasic insulin lispro 50/50 & ND & -1.01 & & 3.98 & 1.05 & ND & 44 \\
\hline & $\begin{array}{l}\text { before breakfast and lunch } \\
\text { and biphasic insulin lispro } \\
25 / 75 \text { before dinner }(n=60)^{1}\end{array}$ & & $P=0.008$ & & $P=0.001$ & $P=0.36$ & & $P=0.103$ \\
\hline
\end{tabular}


- Insulin glargine and prandial insulin lispro produced similar reductions in $\mathrm{HbA}_{1 \mathrm{c}}$ levels, but insulin glargine was associated with significantly lower FBG levels, nocturnal blood glucose, and a lower incidence of hypoglycemia (as well as fewer injections and less self-monitoring of blood glucose levels), whereas insulin lispro produced better control of postprandial blood glucose levels (Bretzel et al. 2006).

- Based on findings from an observational analysis using data from UK general practices, insulin glargine $(n=2875)$ tended to produce slightly improved diabetes control than insulin detemir $(n=361)$ and less hypoglycemia (Currie et al. 2007).

\section{Glycemic control in adults: "treatment approach"}

In a large clinical trial, Davies et al. (2005) compared two treatment approaches with insulin glargine in $>4000$ patients with type 2 diabetes. As in most other clinical trials insulin dosage was titrated to specific FBG targets and the aim of this trial was to compare investigator/physician-led titration with patient self-managed titration over a 24-week period. Interestingly, the self-managed approach to insulin glargine dose titration resulted in higher dosages of insulin being administered and this was associated with better glycemic control (as measured by $\mathrm{HbA}_{1 \mathrm{c}}$ and $\mathrm{FBG}$ levels) and an increase in symptomatic hypoglycemia (but not severe or nocturnal episodes).

More recently, Kennedy et al. (2006) assessed glycemic control using a combination of active versus usual algorithmic titration approaches, and point-of-care versus laboratory measurement of $\mathrm{HbA}_{1 \mathrm{c}}$. This trial included $>7500$ patients with type 2 diabetes treated for a period of 24 weeks; the best results in terms of lowering of FBG (self-monitored) and proportion of patients with $\mathrm{HbA}_{1 \mathrm{c}}$ levels $<7 \%$ was achieved with active titration and point-of-care monitoring. Active titration was defined as weekly patient contact (telephone, fax, email) to review general wellbeing, review glucose values, and reinforce insulin titration; this was in addition to the usual titration that occurred every 6 weeks.

\section{Quality of life}

Diabetes mellitus is a chronic, often debilitating disease which can affect many aspects of day-to-day life. In its most severe forms, when poorly controlled, the disease is associated with longer-term microvascular (retinopathy, neuropathy, and nephropathy) and macrovascular complications. Treatment should be multifactorial so as to achieve optimal control of the underlying disease, and to alleviate symptoms and minimize risk of long-term complications. This in itself may impact the patient's wellbeing, but it is further confounded by the side effects of intensive glycemic treatment such as potentially disabling hypoglycemia, weight gain, and increased cost to the patient.

In clinical trials a number of authors commented on the positive impact of insulin glargine on patient wellbeing and its acceptance by patients (Schober et al. 2002; Doyle et al. 2004; Colino et al. 2005; Herman et al. 2005; Home et al. 2005; Bretzel et al. 2006; Eliaschewitz et al. 2006; Meneghini et al. 2006; Chaterjee et al. 2007). As part of a formal analysis of treatment satisfaction and physiologic wellbeing, Witthaus et al. (2001) assessed 517 patients with type 1 diabetes participating in an $\mathrm{RCT}$ in Europe using the Diabetes Treatment Satisfaction Questionnaire (DTSQ) and the Well-Being Questionnaire (W-BQ). After 28 weeks' therapy, insulin glargine produced an improvement in "treatment satisfaction" which was significantly superior to that produced by NPH insulin (difference between treatments was 1.83 points; $P<0.001$ ). Both insulin preparations decreased "perceived frequency of hyperglycemia" scores but the effect was significantly more pronounced with insulin glargine $(P=0.037)$. Psychologic wellbeing scores were improved equally by insulin glargine and NPH insulin. These findings were augmented by those of Manini et al. (2007) who reported significant improvements in Well-being Enquiry for Diabetics (WED) related to discomfort $(P=0.02)$, impact $(P=0.0002)$, and total score $(P=0.0005)$ in 40 type 1 diabetic patients switched from NPH insulin to insulin glargine because of suboptimal control. The health-related quality of life (HRQL)-WED questionnaire was undertaken at 6-8 months after switching to insulin glargine, at which stage there was a perceived lower risk of hypoglycemia and less problems in daily life with insulin glargine and, importantly, $\mathrm{HbA}_{1 \mathrm{c}}$ was reduced by $0.7 \%$ $(P<0.0001$ vs baseline).

Similarly, in a general practice study involving 135 patients with type 1 diabetes and 180 patients with type 2 diabetes, insulin glargine produced significant improvements in HRQL in a subset of 50 patients who completed the survey (Fischer et al. 2004). Statistically significant improvement was recorded for scores relating to total symptoms $(34.8 \% ; P<0.0001)$, total symptom distress $(42.6 \% ; P<0.0001)$, overall wellbeing $(P=0.002)$, and emotional wellbeing $(P=0.003)$ compared with baseline values. These improvements in $\mathrm{QOL}$ were associated with significantly improved glycemic control as assessed by $\mathrm{HbA}_{1 \mathrm{c}}$ levels (reduced by $0.28 \pm 1.47, P=0.03$, in type 1 diabetic patients; and reduced by $0.6 \pm 1.51, \quad P<0.0001, \quad$ in type 2 diabetic patients).

Meneghini and coworkers (2006) assessed HRQOL in 230 type 2 diabetic patients treated with insulin glargine $(n=112)$ or pioglitazone $(n=118)$, as add-on therapy, over a period of 48 weeks. Insulin glargine produced greater improvement in 17 of $20 \mathrm{HRQL}$ measures from baseline to week 48 compared with pioglitazone. The results were statistically significant $(P<0.05)$ for domains measuring psychologic distress related to hyperglycemic symptoms, fatigue, and total symptom-related distress. Using multivariate analysis insulin glargine was associated with significantly better outcomes for hyperglycemic and ophthalmologic symptoms, and for psychologic distress related to fatigue, hyperglycemic, hypoglycemic, ophthalmologic, and cardiovascular symptoms. Similar findings were recently reported by Vinik and Zhang (2007) in a randomized, multicenter study comparing insulin glargine and rosiglitazone as add-on therapy in 217 patients with poorly controlled type 2 diabetes 
despite being treated with a sulfonylurea plus metformin. The two drugs were equally effective in terms of improving glycemic control, but insulin glargine produced significantly greater benefits over rosiglitazone in the Diabetes Symptom Checklist-Revised (DSC-R) total symptom score $(P=0.005)$, total distress score $(P=0.03)$, and individual domain scores for mood symptoms ( $P=0.007)$, ophthalmologic symptoms $(P=0.007)$, ophthalmologic distress $(P=0.013)$, fatigue distress $(P=0.033)$, and Short Form-36 (SF-36) perception of general health $(P=0.047)$. Finally, in a randomized, multicenter, 26-week clinical trial once-daily insulin glargine $(n=227)$ and twice-daily exenatide $(n=228)$ were found to be equally efficacious in terms of glycemic control and improving QOL as assessed by DSC-R, DTSQ, and the SF-36 vitality subscale (Secnik Boye et al. 2006).

\section{Tolerability and safety of insulin glargine}

According to the Physicians' Desk Reference (PDR) the adverse reactions most commonly associated with insulin glargine include:

- body as a whole-allergic reaction

- skin and appendages-injection site reaction, lipodystrophy, pruritus, rash

- other-hypoglycemia.

In one of the largest studies published to date, 7893 patients with type 2 diabetes were randomized to treatment with insulin glargine (comparing active vs usual algorithmic titration, and point-of-care vs laboratory measurement of $\mathrm{HbA}_{1 \mathrm{c}}$ ) for a period

\section{Table 7 | Summary of safety data from a large clinical trial} involving $>7000$ patients with type 2 diabetes treated with insulin glargine for 24 weeks (Kennedy et al. 2006)

\begin{tabular}{|c|c|}
\hline No. of patients & Study group \\
\hline 7893 & $\begin{array}{l}\text { Adults with type } 2 \text { diabetes treated with } \\
\text { insulin glargine }\end{array}$ \\
\hline 7605 (96.4\%) & $\begin{array}{l}\text { Safety population [7893: patients with no } \\
\text { data }(n=169) \text { or who did not receive treatment } \\
(n=119)]\end{array}$ \\
\hline $2737(35 \%)$ & Reported at least one $\mathrm{AE}$ related to treatment \\
\hline 751 (10\%) & $\begin{array}{l}\text { Reported one } A E \text { that was assessed as being } \\
\text { possibly related to insulin glargine }\end{array}$ \\
\hline $642(8 \%)^{\mathrm{a}}$ & $\begin{array}{l}\text { Reported at least one } A E \text { that was classified } \\
\text { as serious }\end{array}$ \\
\hline $129(1.7 \%)$ & $\begin{array}{l}\text { Serious AEs assessed as being possibly } \\
\text { related to insulin glargine and of these only } \\
\text { hypoglycemia occurred in }>0.1 \% \text { of patients }\end{array}$ \\
\hline $35(0.5 \%)$ & $\begin{array}{l}\text { Deaths; the majority due to cardiovascular } \\
\text { events and none were assessed as being } \\
\text { caused by insulin glargine }\end{array}$ \\
\hline \multicolumn{2}{|c|}{$\begin{array}{l}\text { aSerious AEs reported by }>0.1 \% \text { of patients were hypoglycemia }(2.1 \%) \text {; cardiac failure } \\
(0.6 \%) \text {; chest pain }(0.5 \%) \text {; coronary artery disease }(0.5 \%) \text {; cellulitis }(0.4 \%) \text {; pneumonia } \\
(0.4 \%) \text {; myocardial infarction }(0.3 \%) \text {; transient ischemic attacks }(0.2 \%) \text {; cerebrovascular } \\
\text { accident }(0.2 \%) \text {. Ninety-five patients }(1.2 \%) \text { discontinued treatment because of a serious } A E \text {. } \\
\text { AE, adverse event. }\end{array}$} \\
\hline
\end{tabular}

of 24 weeks (Kennedy et al. 2006). No unexpected findings in the frequency or spectrum of adverse events were observed in this trial, with hypoglycemia being the most frequent serious adverse event (Table 7). Similar results were reported by Davies et al. (2005) in a study involving almost 5000 patients with type 2 diabetes treated with insulin glargine for 24 weeks. In this study $11 \%$ of patients reported an adverse event which was considered possibly related to insulin glargine and the majority of these were mild injection site reactions.

In the longest clinical trial reported thus far, patients with type 2 diabetes were treated with insulin glargine or NPH insulin for an initial 1-year period (Massi Benedetti et al. 2003) and followed for a further 28 months (Kacerovsky-Bielesz et al. 2006). As can be seen in Table 8, the incidence of adverse events was similar between the two treatment groups. During the extension study, insulin glargine was well tolerated with only four patients reporting adverse events that were considered possibly related to treatment (Kacerovsky-Bielesz et al. 2006).

Table 8 | Safety profile in patients with type 2 diabetes treated with insulin glargine or NPH insulin for 1 year (Massi Benedetti et al. 2003)

\begin{tabular}{|lcc|}
\hline Safety parameter & Insulin glargine (n=289) & NPH insulin (n=281) \\
\hline At least one AE & $65 \%$ & $65 \%$ \\
$\begin{array}{l}\text { AE possibly related } \\
\text { to medication }\end{array}$ & $5.5 \%$ & $7.5 \%$ \\
Injection site reactions & $2.4 \%$ & $3.2 \%$ \\
Metabolic/nutritional AE & $1.7 \%$ & $2.5 \%$ \\
Change in bodyweight & $+2.01 \mathrm{~kg}$ & $+1.88 \mathrm{~kg}$ \\
Antibodies against IG & $+0.9 \%{ }^{\mathrm{a}}$ & $+5.9 \%$ \\
Antibodies against NPH & $+0.5 \%{ }^{\mathrm{a}}$ & $+6.3 \%$ \\
\hline aStatistically significant difference between IG and NPH. & \\
AE, adverse event; IG, insulin glargine; NPH, neutral protamine hagedorn. & \\
\hline
\end{tabular}

Schober et al. (2002) reported on the tolerability of insulin glargine and NPH insulin as part of basal/bolus regimens administered for 6 months to 349 children/adolescents (aged 5-16 years) with type 1 diabetes. Both drugs were well tolerated, but there were fewer serious adverse events in the insulin glargine group $(5.8 \%$ vs $13.7 \%)$. None required discontinuation of therapy.

Finally, two clinical trials compared insulin glargine as third-line therapy with rosiglitazone (Rosenstock et al. 2006) or exenatide (Heine et al. 2005) in type 2 diabetic patients with poor glycemic control. Adverse events possibly related to treatment were significantly more frequent with rosiglitazone $(28.6 \%$ vs $6.7 \% ; P<0.0001)$. Compared with exenatide, insulin glargine was associated with a significantly lower incidence of gastrointestinal side effects, most notably nausea $(8.6 \%$ vs $57.1 \% ; P<0.001)$, and vomiting (3.7\% vs $17.4 \% ; P<0.001)$. Since nausea and vomiting may predispose diabetic patients 
(usually type 1) to ketoacidosis, this is clearly an important finding, Separately, one case of nausea and vomiting has been reported in a type 1 diabetic patient treated with insulin glargine (Dixon \& Bain 2005).

Within the published clinical literature the most commonly discussed tolerability and safety issues associated with the treatment of diabetic patients with insulin include: symptomatic hypoglycemia, injection site reactions, possible immunogenicity, effects on bodyweight, and possible progression of retinopathy. These will be discussed separately based mainly on the evidence of the large clinical trials cited in Tables 3 to 6 .

\section{Symptomatic hypoglycemia}

Aggressive titration of insulin to achieve tight glycemic control is hampered by the potential occurrence of hypoglycemic episodes. Indeed, hypoglycemia is the most frequent acute complication of intensive insulin therapy in patients with type 1 diabetes (Ratner et al. 2000).

The incidence of symptomatic and/or nocturnal and severe hypoglycemia was reviewed in the Clinical efficacy section (Tables 3, 4, and 6). While not all clinical trials demonstrated a statistically significant advantage for insulin glargine over comparator insulin regimens (mostly NPH insulin) in patients with type 1 or type 2 diabetes, there is a clinically significant trend in favour of glargine. Thus, in the 17 large controlled trials reviewed in Tables 3, 4, and 6, 14 trials identified a significantly lower occurrence of hypoglycemia with insulin glargine; two trials noted no difference between insulin glargine and NPH insulin. The final trial reported a lower incidence of nocturnal hypoglycemia with premixed biphasic insulin lispro 25/75 despite a lower incidence of symptomatic hypoglycemia with insulin glargine (Malone et al. 2005).

Overall, there appears to be a clinically relevant trend toward fewer hypoglycemic episodes (including nocturnal hypoglycemia) with insulin glargine compared with more traditional insulins such as NPH. The low rate of hypoglycemic episodes has been confirmed in large studies (involving a total of $>10000$ patients) comparing different treatment algorithms of insulin glargine in patients with type 2 diabetes (Davies et al. 2005; Kennedy et al. 2006) and in a meta analysis comparing insulin glargine with NPH insulin (Rosenstock et al. 2005).

\section{Injection site reactions}

Apart from hypoglycemia, the most common adverse event reported in clinical trials published to date has been a reaction at the site of injection; this applies to comparator insulin products as well as insulin glargine. The type of injection site reaction has been further subdivided to include: pain hemorrhage, mass, or "reaction." Reviewing all the large clinical trials included in Tables 3,4 , and 6 revealed no clinically significant trend with regards to this adverse effect, with all authors concluding that the episodes were mild and did not require discontinuation of treatment. In four trials, injection site pain was more common in patients treated with insulin glargine that in those receiving NPH insulin (Raskin et al. 2000; Ratner et al. 2000; Rosenstock et al. 2001; Hershon et al. 2004), but in all cases the effect was considered mild and once again did not require discontinuation of treatment. There is some evidence that with time and perhaps developing a better injection technique (regular rotation of the injection site), local reactions are not a clinical concern. For example, Massi Benedetti et al. (2003) reported an incidence of injection site reactions of $3.1 \%$ in insulin glargine-treated patients $(n=289$; one patient discontinued therapy) and $3.9 \%$ in NPH insulin-treated patients $(n=281)$. A total of 239 patients from the insulin glargine group entered a long-term follow-up study of up to 28 months' duration and no adverse events concerning the injection site were recorded; specifically there were no reports of pain (Kacerovsky-Bielesz et al. 2006).

In a study involving 349 children/adolescents (aged 5 to 16 years) treated with insulin glargine or NPH insulin for 6 months there was no difference between the two treatments with respect to injection site adverse reactions classified as atrophy, fibrosis, hemorrhage, mass, pain, or reaction (Schober et al. 2002). It has been speculated that patients perceive more pain during subcutaneous administration of acidic solutions (such as insulin glargine; $\mathrm{pH}$ 4.0). In this regard Karges and colleagues (2006) compared insulin glargine (acidic) with NPH (neutral) in 112 children/adolescents aged 7-21 years with type 1 diabetes. There was no significant difference in pain perception between the two treatments and pain scores were also very similar to those associated with the injection of short-acting regular insulin.

\section{Retinopathy}

Diabetes mellitus is a leading cause of blindness in the adult population and the most effective treatment is prevention by means of tight control of blood glucose levels and blood pressure (Powers 2005). Regular eye examinations are essential for all patients with diabetes mellitus (type 1 or 2) and careful monitoring is crucial when new therapies are introduced. Initially it was thought that the high binding affinity of insulin glargine for insulin-like growth factor (IGF)-1 receptors may adversely impact the progression of retinopathy in diabetic patients (Chakkarwar \& Manjrekar 2005). However, clinical studies have not observed any such changes.

The most extensive data for insulin glargine derives from a retrospective analysis of clinical trials involving data from 2207 patients who were treated with insulin glargine or NPH insulin for 28 to 52 weeks (McKeage \& Goa 2001). Overall, the panel of experts who reviewed the data concluded that there was no increased risk toward retinopathy with insulin glargine compared with NPH insulin. While individual studies reported higher rates of new macular edema and $a \geq 3$-step change in progression of retinopathy (both using photographic methods) with insulin glargine, there were no reports of optic disc swelling in any of the treatment groups (McKeage \& Goa 2001). In published studies reviewed in the clinical sections, there has been no reported increased risk of development or progression of diabetic 
retinopathy for insulin glargine compared with NPH insulin (Raskin et al. 2000; Home et al. 2005).

\section{Bodyweight}

Good nutritional balance, paying particular attention to bodyweight, is a prerequisite for optimal treatment programs in patients with type 1 and type 2 diabetes mellitus. Unfortunately, in patients with type 2 diabetes, obesity is a common underlying problem and such patients frequently fail to adhere to dietary control and exercise programs/recommendations. Consequently, it is important to monitor changes in bodyweight to minimize possible cardiovascular risk. Weight gain is a common problem associated with insulin replacement therapy (Chakkarwar \& Manjrekar 2005). In the case of insulin glargine, changes in bodyweight reported in clinical trials were generally small with no clinically significant differences between insulin glargine and NPH insulin in patients with type 2 diabetes. In two large studies involving a total of $>10000$ patients with type 2 diabetes, insulin glargine for 24 weeks resulted in an increase in mean bodyweight of between 1 and $2 \mathrm{~kg}$ (Davies et al. 2005; Kennedy et al. 2006). A similar finding was documented following 1 year of treatment with insulin glargine $(+2.12 \mathrm{~kg}$ vs baseline) in patients with type 2 diabetes (Massi Benedetti et al. 2003). Interestingly, with continued treatment for at least a further 28 months no further increase in bodyweight was observed (+2.02 kg vs baseline) (KacerovskyBielesz et al. 2006). In contrast, in an observational study undertaken in Germany involving $>12000$ patients suboptimally treated with oral antidiabetic drugs, body mass index decreased slightly in patients treated with insulin glargine compared with those who continued titration with oral therapy.

\section{Insulin antibodies}

A possible concern with the administration of a foreign protein such as insulin glargine is the potential to induce an immunogenic response. However, none of the studies (16 weeks to $>3$ years) that assessed antibody levels showed any evidence of such a reaction (Pieber et al. 2000; Raskin et al. 2000; Ratner et al. 2000; Yki-Järvinen et al. 2000; Rosenstock et al. 2001; Schober et al. 2002; HOE 901/2004 Study Investigators Group 2003; Massi Benedetti et al. 2003; Home et al. 2005; Kacerovsky-Bielesz et al. 2006).

The majority of these clinical trials reported a similar lack of effect for insulin glargine and NPH insulin on antibody titers. However, four trials reported that insulin glargine was potentially less immunogenic than NPH insulin (Raskin et al. 2000; Yki-Järvinen et al. 2000; Rosenstock et al. 2001; Massi Benedetti et al. 2003). In the longest study, insulin glargine administered for $\geq 28$ months did not increase mean insulin glargine antibody levels or mean human insulin antibody levels following an initial 52-week comparative study. Indeed, with time, antibody levels slightly decreased (Kacerovsky-Bielesz et al. 2006).

\section{Economic evidence}

Economic assessments in diabetes can take a variety of perspectives depending on the type of patient, the healthcare system/country involved, the scientific/economic question being tested, and the type of study (RCT vs everyday practice). With regards to interpretation of such studies it is important to recognize that findings from one healthcare system may not necessarily apply to a different healthcare system. In most clinical scenarios the RCT is the benchmark for establishing scientific "best evidence," and there has been a tendency for health economists to use such trials to perform economic evaluations. However, the rigidity of RCTs creates limitations with respect to representing "real world" everyday practice. In such situations observational studies involving large cohorts of patients using the test products on a day-by-day basis provides valuable information about drug usage and its impact on patients outside the artificial confines of a clinical trial (Dixon \& Peters 2007). For insulin glargine a number of RCTs and observational economic studies have recently been published (Table 9).

\section{Type 1 diabetes mellitus}

McEwan and colleagues (2007a) compared insulin glargine with $\mathrm{NPH}$ insulin using a sophisticated model incorporating risk factors from major clinical trials such as the DCCT trial and Framingham studies. Based on two possible clinical scenarios (reduced hypoglycemia or reduced $\mathrm{HbA}_{1 \mathrm{c}}$ ), cost and health outcomes for a cohort of 10000 patients treated for 40 years were forecast. This model demonstrated significant benefits for insulin glargine and the incremental cost effectiveness was found to be similar to that presented in the original NICE submission, thus reaffirming the overall value for money of insulin glargine and the significant health benefits that it provides. Comparable results from a Canadian payer perspective were reported by Grima and colleagues (2007) (Table 9).

The two remaining economic analyses with insulin glargine in patients with type 1 diabetes were comparisons with insulin detemir - one in the US and one in the UK-and produced very divergent results.

Valentine and colleagues (2006) in the US applied economic data to a single RCT in which insulin detemir was found to produce significantly less hypoglycemia than insulin glargine. Costs applied to a Center for Outcomes Research (CORE) diabetes model highlighted significant health economic advantages for insulin detemir. In comparison with insulin glargine, insulin detemir increased quality-adjusted life expectancy by 0.063 quality-adjusted life-years (QALYs), and reduced both direct and indirect medical costs. In contrast Poole et al. (2007) in the UK reported that the total cost of treatment was $10 \%$ lower for insulin glargine compared with insulin detemir (£132/patient per year; $P<0.001)$. These data were derived from an observational study involving type 1 diabetic patients treated for at least 6 months with insulin 
Table 9 | Summary of economic studies involving insulin glargine in the treatment of patients with type 1 and type 2 diabetes mellitus

$\begin{array}{lllll}\text { Reference } & \text { Country/healthcare system Economic objective } & \text { Economic model } & \text { Results and conclusions }\end{array}$

Assessments in patients with type 1 diabetes

McEwan et al. 2007a UK/NHS CE/CU comparison of IG Simulated outcomes
and NPH insulin model using DCCT and

Grima et al. 2007

Canada/public payer perspective

CE/CU comparison of IG and NPH insulin

Prescription costs and total cost of treatment or IG and ID

Poole et al. 2007

UK/NHS

Valentine et al. 2006

US/Medicare

CE/CU comparison of IG and ID Framingham data with meta analysis of RCT of IG vs NPH results

The incremental CE ratio for IG vs $\mathrm{NPH}$ insulin ranged from £2695 to $£ 10$ 943; consistently below the $£ 20$ 000/QALY considered cost effective by the NHS. Compared with NPH, IG was highly cost effective and provided significant health benefits

Simulated outcomes model to which results from a RCT of IG vs NPH were incorporated

IG resulted in greater life-years gained (0.21-0.24) and QALYs (0.17-0.2) compared with NPH. The weighted incremental cost per life-year and QALY gained were \$Can18 661 and $\$ C a n 20$ 799. These data provide strong support for the adoption of IG from a Canadian payer view

Analysis of treatment costs (drugs, reagents, syringes, sharps, hypoglycemia rescue medication) for patients treated with IG $(n=625)$ ID $(n=268)$, THIN data

The volume of IG prescribed was consistently lower with IG than with ID and the total cost of treatment was $10 \%$ lower for IG compared with ID (£132/patient per year; $P<0.001)$

CORE Diabetes Model incorporating clinical data from a single RCT of IG vs ID
Compared with IG, ID increased quality-adjusted life expectancy by 0.063 QALYS, and reduced direct medical costs by $\$$ US2072 and indirect costs by $\$$ US3103

Assessments in patients with type 2 diabetes

McEwan et al. 2007b UK/NHS

CE/CU comparison of IG and NPH insulin

CE/CU comparison of IG and NPH insulin
Simulated outcomes model using UKPDS study data, data from the THIN database and two meta analyses comparing IG vs NPH

Grima et al. 2007

Canada/public payer perspective
Simulated outcomes model using UKPDS data to which results from a RCT of IG vs NPH were incorporated

Prescription costs and total cost of treatment for IG and ID

CE/CU comparison of IG and biphasic insulin aspart Mix 30
Analysis of treatment costs (drugs, reagents, syringes, sharps, hypoglycemia rescue medication) for patients treated with IG $(\mathrm{n}=977)$ or ID ( $n=334)$, THIN data

Costs applied to the INITIATE RCT (IG, $\mathrm{n}=116$; Mix 30, $\mathrm{n}=117$ ) and input into a validated Markov/MonteCarlo simulation model
The incremental CE ratio for IG vs NPH insulin was $£ 10$ 027/QALY in one model and $£ 13$ 921/QALY in another; consistently below the $£ 20$ 000/QALY considered cost effective by the NHS. Compared with NPH, IG was highly cost effective and provides excellent value for money for the treatment of type 2 diabetes in the UK

IG resulted in greater life-years gained (0.52-0.59) and QALYs (0.48-0.52) compared with NPH. The weighted incremental cost per life-year and QALY gained were $\$ C a n 8041$ and $\$ C$ an8618. These data provide strong support for the adoption of IG from a Canadian payer view

In type 2 diabetics the median cost for antidiabetic therapy was $28.1 \%$ lower in patients treated with IG than in those treated with ID ( 1014 vs $£ 1410 /$ patient per year; $P<0.001)$

This study suggests that long-term treatment with biphasic aspart Mix 30 in insulin-naïve type 2 diabetic patients as part of a triple-therapy regimen may have economic advantages over IG. The authors acknowledge the limitations of the clinical trial which was of short duration and included a relatively young cohort of patients 
table continued...

\begin{tabular}{lllll}
\hline Reference & Country/healthcare system & Economic objective & Economic model & Results and conclusions \\
\hline Lechleitner et al. 2005 & Austria/general practice & Total cost of treatment with & Simulated outcomes & Observational study comparing IG \\
& & IG and conventional insulins. & model using DCCT and & with conventional insulin therapy to \\
& Treatment and dosage were & Framingham data with & which appropriate costs were applied
\end{tabular}

Bullano et al. 2006

US/general practice

based on everyday practice

Comparison of the cost of managing hypoglycemia in inpatients treated with IG or a premixed fixed dose combination product

Rosenstock et al. 2006

US/general practice

US/general practice

To compare the total cost of maintaining glycemic control in patients using IG or pioglitazone added to oral monotherapy
To compare the total cost of maintaining glycemic control in patients using IG or rosiglitazone in a triple therapy regimen meta analysis of RCT of IG vs NPH results

An observational analysis involving patients treated with IG ( $n=1212)$ or a premixed fixed-dose combination product $(n=1103)$ identified using a claims database. Cost of managing hypoglycemia in patients

Cost analysis applied to a RCT comparing IG (n=105) and rosiglitazone $(n=112)$ in triple therapy regimens
Type 2 diabetic patients recently starting IG therapy had a lower rate of hypoglycaemia than patients using fixed-dose insulin combination products

(7 vs 13.8 patients/year; $P=0.027$ ). The authors calculated that treatment of 15 patients with IG would avoid one hypoglycemic event per year compared with the premixed combination products

The cost of maintaining glycemic control was significantly lower with IG than with rosiglitazone (IG saved \$US235 over a period of 24 weeks). Furthermore the authors calculated that the mean cost per $1 \%$ reduction in $\mathrm{HbA}_{1 \mathrm{c}}$ was $\$ U \mathrm{US} 824$ for IG and \$US1062 for rosiglitazone; an important finding given that medical resource utilization may further decrease as a result of improved glycemic control

Cost analysis applied to a RCT comparing IG $(n=118)$ and pioglitazone $(n=112)$ as add-on therapy
IG added to monotherapy in patients with poorly controlled type 2 diabetes improved clinical outcomes such as glycemic control and quality of life. The estimated mean total cost of glycemic control over 48 weeks was \$US379 less for IG-treated patients (\$US1721 vs \$US2100 for pioglitazone)

CE, cost-effectiveness evaluation; CORE, Center for Outcomes Research; CU, cost-utility evaluation; DCCT, Diabetes Control and Complications Trial; ID, insulin detemir; IG, insulin glargine; NHS, National Health Service; NPH, neutral protamine hagedorn; OAD, oral antidiabetic drug; QALY, quality-adjusted life-year; RCT, randomized clinical trial; THIN, The Health Improvement Network; UKPDS, UK Prospective Diabetes Study.

glargine or insulin detemir and who were included on the THIN database. Data were extracted from the same time period to avoid biases occurring as a result of changes in the rapidly evolving nature of diabetes-related clinical practice. Interestingly, the cost of hypoglycemia rescue medication was $25 \%$ lower with insulin glargine $(P=0.052)$. Overall the authors calculated that based on these findings, treating 1000 patients for 1 year with insulin glargine would save £132 000 compared with insulin detemir.

Warren and colleagues (2004) assessed the economic evaluation presented with the original NICE submission of insulin glargine and published revised cost-effectiveness figures. They recognize that the model is highly sensitive to clinical assumptions such as the amount of utility gained by reducing patients' fear of hypoglycemia. Overall they concluded that compared with NPH insulin, insulin glargine is effective in reducing the incidence of nocturnal hypoglycemia, but since there does not appear to be any improvement in long-term glycemic control, insulin glargine is unlikely to reduce the incidence of long-term microvascular and cardiovascular complications associated with the disease. This latter conclusion can be questioned based on more recent findings with more aggressive treatment algorithms, and it will be interesting to see whether longer-term therapy with insulin glargine can impact microvascular/cardiovascular endpoints beyond that achieved with conventional insulins.

\section{Type 2 diabetes mellitus}

McEwan and colleagues (2007) compared insulin glargine with NPH insulin using a sophisticated model incorporating evidence from the UK Prospective Diabetes Study to simulate disease progression, data from the THIN database for patient 
characteristics, and appropriate outcomes results from pivotal clinical trials. The incremental cost-effectiveness ratio for insulin glargine versus NPH insulin was $£ 10$ 027/QALY in one model (based on hypoglycemia) and £13 921/QALY in another (based on $\mathrm{HbA}_{1 \mathrm{c}}$ ); consistently below the $£ 20$ 000/QALY considered cost effective by NICE. The authors concluded that compared with NPH, insulin glargine was highly cost effective and provides excellent value for money for the treatment of type 2 diabetes in the UK. These findings were reinforced by Grima et al. (2007) who undertook a similar analysis, but from a payer perspective, in Canada (Table 9). Poole and colleagues (2007), again using observational data from the THIN database, reported that in type 2 diabetics the median cost for antidiabetic therapy was $28.1 \%$ lower in patients treated with insulin glargine compared with those treated with insulin detemir ( $£ 1014$ vs $£ 1410 /$ patient per year; $P<0.001)$.

Bullano and colleagues (2006) in the US reported that type 2 diabetic patients recently starting glargine therapy had a lower rate of hypoglycemia than patients using fixed-dose insulin combination products ( 7 vs 13.8 patients/year; $P=0.027$ ) and calculated that treatment of 15 patients with insulin glargine would avoid one hypoglycemic event per year compared with the premixed combination insulins.

In a US study long-term treatment with biphasic aspart Mix 30 in insulin-naïve type 2 diabetic patients as part of a triple-therapy regimen was more cost effective than insulin glargine, with an incremental cost-effectiveness ratio of \$US46 533 per QALY. The authors acknowledge the limitations of the clinical trial which was of short duration and included a relatively young cohort of patients (Ray et al. 2007). Lechleitner and colleagues (2005) found that total daily costs were similar for insulin glargine and conventional insulins, although the glargine group used significantly lower doses of insulin and required fewer blood glucose test strips.

Finally, in two clinical trials the total cost of achieving glycemic control was lower for insulin glargine than for rosiglitazone (Rosenstock et al. 2006) or pioglitazone (Meneghini et al. 2006) as add-on therapy in patients with type 2 diabetes poorly controlled with oral therapy.

\section{Clinical value}

Diabetes mellitus is a chronic disease associated with high morbidity and mortality as a result of microvascular and macrovascular complications. Today it represents a major public health concern of almost epidemic proportions and this picture is forecast to worsen as patient populations become older and are associated with a greater prevalence of risk factors (Chan \& Abrahamson 2003; Powers 2005). This will increase the burden on health services, which are already under pressure. It almost goes without saying that any intervention that can improve patient care and reduce clinic/hospital visits will not only relieve some of this burden, it will also likely have a positive impact on patient QOL and wellbeing.
The Diabetes Control and Complications Trial (DCCT Research Group 1993) provided convincing evidence that tight and sustained management of glycemia using an intensive therapy regimen and regular follow-up/monitoring, reduces both the development and progression of microvascular complications. These findings form the basis for most treatment guidelines used in the care of diabetic patients. One of the biggest challenges facing the physician and patient when using intensive insulin regimens is to achieve optimal glycemic control without provoking episodes of hypoglycemia which could potentially be fatal.

Hypoglycemia is thought to occur at times corresponding with peak plasma insulin concentrations, and insulin glargine with its relatively flat plasma concentration-versus-time profile, with no pronounced peaks over 24 hours, may therefore have an advantage. It might also facilitate a more physiologic approach to diabetes management with basal insulin glargine providing a constant level of insulin throughout the day, and bolus insulin being used to provide prandial cover.

In the setting of type 1 diabetes, basal/bolus treatment with insulin glargine (once daily) has proven to be at least as effective as conventional once- or twice- daily treatment with NPH insulin with a trend toward less hypoglycemia. This evidence was reviewed by NICE in the UK (NICE 2002) which concluded:

"On the balance of effectiveness and cost-effectiveness evidence, insulin glargine, which has a peakless action profile, is also recommended as a long-acting preparation for people with type 1 diabetes; some studies in this review show significantly lower FBG with insulin glargine than isophane (NPH) insulin and others suggest that people on insulin glargine may experience fewer hypoglycemic events than people receiving once-daily isophane (NPH) insulin."

More recent clinical trials have confirmed these findings in studies of long duration and added to our understanding of the value of insulin glargine showing that:

- it can be administered at other times of the day with equal effect (the initial recommendation was for it to be given at bedtime)

- it is effective and well tolerated in children and adolescents

- it is a suitable replacement for continuous subcutaneous insulin infusions during pump-free periods associated with pump malfunction, adverse effects, or physical activity.

Type 2 diabetes has traditionally been treated in a stepwise manner with lifestyle modifications such as diet and exercise being a cornerstone of day-to-day management. If this fails to achieve the desired level of glycemic control, then oral antidiabetic drugs can be introduced (alone or in combination). Insulin has generally only been considered if the above steps fail. Insulin glargine has been studied in a number of large clinical trials involving patients poorly controlled by lifestyle changes and oral antidiabetic therapy, and it was shown to be at least as effective as NPH insulin with the clinically important advantage of causing significantly fewer episodes of nocturnal hypoglycemia. 
Economic analyses with insulin glargine have confirmed the findings of the original NICE assessment, and economic models applied to UK and Canadian healthcare systems have demonstrated its cost effectiveness relative to NPH insulin in patients with type 1 and type 2 diabetes. Equally important, a number of studies have shown that insulin glargine has a positive impact on patient satisfaction, wellbeing, and other measures of QOL. In this regard it was shown to be significantly superior to $\mathrm{NPH}$ insulin in type 1 diabetes, and to pioglitazone and rosiglitazone in type 2 diabetes.

In summary, there is now a wealth of evidence, including official recommendations, well-controlled clinical trials, and large observational studies in everyday practice highlighting the suitability of insulin glargine as a first-line choice as a basal insulin replacement in patients with type 1 diabetes mellitus, including children and adolescents. There is also convincing evidence for its efficacy and safety in patients with type 2 disease who require insulin treatment to achieve glycemic control.

Future studies should be directed toward establishing the efficacy and safety of insulin glargine in the long term since it is a life-long therapy for most patients. It will also be interesting to see whether the potential for more intense glycemic control correlates with a significant delay in the progression of microvascular/macrovascular complications and improves long-term survival rates. Results from long-term studies assessing cardiovascular risk/outcomes in large cohorts of patients, such as ORIGIN (Skyler 2004) and HEART2D (Milicevic et al. 2005) are awaited with interest.

\section{Acknowledgments}

The authors declare that they have no conflict of interest.

\section{References}

AACE (American Association of Clinical Endocrinologists). State of diabetes complications in America. Available at: http://www.stateofdiabetes.com (accessed January 2007).

ADA (American Diabetes Association). 2007 resource guide - a supplement to diabetes forecast. Available at: http://diabetes.org/diabetes-forecast/resourceguide.jsp (accessed January 2007).

Alemzadeh R, Berhe T, Wyatt DT. Flexible insulin therapy with glargine insulin improved glycemic control and reduced severe hypoglycemia among preschool-aged children with type 1 diabetes mellitus. Pediatrics. 2005;115:1320-1324.

Ashwell SG, Gebbie J, Home PD. Optimal timing of injection of once-daily insulin glargine in people with type 1 diabetes using insulin lispro at meal-times. Diab Med. 2006a;23:46-52.

Ashwell SG, Gebbie J, Home PD. Twice-daily compared with once-daily insulin glargine in people with type 1 diabetes using meal-time insulin aspart. Diabet Med. 2006b;23:879-886.

Bode BW, Steed RD, Schleusener DS, Strange P. Switch to multiple daily injections with insulin glargine and insulin lispro from continuous subcutaneous insulin infusion with insulin lispro: a randomized, open-label study using a continuous glucose monitoring system. Endocr Pract. 2005;11:157-164.

Bolli G, Songini M, Trovati M; HOE901/4019 Italian study group. Transfer of patients with type 1 diabetes from NPH insulin to insulin glargine as basal insulin: a multicentre, randomized, parallel-group, open-label study. Diabetologia. 2006;49(Suppl. 1):607. Abstract 0993.
Bretzel RG, Nuber U, El-Haschimi K, Linn T; APOLLO study group. Equivalence of basal insulin glargine versus prandial insulin lispro for glucose control in type 2 diabetes patients on oral agents - results of the APOLLO study. Diabetologia. 2006;49(Suppl. 1):755. Abstract 0145.

Bullano MF, Fisher MD, Grochulski WD, Menditto L, Willey VJ. Hypoglycemic events and glycosylated hemoglobin values in patients with type 2 diabetes mellitus newly initiated on insulin glargine or premixed insulin combination products. Am J Health Syst Pharm. 2006;63:2473-2482.

Chakkarwar PN, Manjrekar NA. Insulin glargine: a long acting insulin analog. J Postgrad Med. 2005;51:68-71.

Chan JL, Abrahamson MJ. Pharmacological management of type 2 diabetes mellitus: rationale for rational use of insulin. Mayo Clin Proc. 2003;78:459-467.

Chase HP, Arslanian S, White N, Usiskin K, Tamborlane W. Insulin glargine (GLAR) vs intermediate-acting insulin in adolescents with type 1 diabetes (T1DM) using multiple daily injection (MDI) therapy. Diabetologia. 2006;49(Suppl. 1):559-560. Abstract 0919.

Chatterjee S, Jarvis-Kay J, Rengarajan T, Lawrence IG, McNally PG, Davies MJ. Glargine versus NPH insulin: efficacy in comparison with insulin aspart in a basal bolus regimen in type 1 diabetes - the glargine and aspart study (GLASS). A randomized cross-over study. Diabetes Res Clin Pract. 2007;77:215-222.

Colino E, López-Capapé M, Golmayo L, Álvarez MA, Alonso M, Barrio R. Therapy with insulin glargine (Lantus ${ }^{\circledR}$ ) in toddlers, children and adolescents with type 1 diabetes. Diabetes Res Clin Pract. 2005;70:1-7.

Currie CJ, Poole CD, Tetlow T, Holmes P, McEwan P. The outcome of care in people with type 1 and type 2 diabetes following switching to treatment with either insulin glargine or insulin detemir in routine general practice in the UK: a retrospective database analysis. Curr Med Res Opin. 2007;23(Suppl. 1):S33-S39.

Davies M, Storms F, Shutler S, Bianchi-Biscay M, Gomis R; AT.LANTUS study group. Improvement of glycemic control in subjects with poorly controlled type 2 diabetes: comparison of two treatment algorithms using insulin glargine. Diabetes Care. 2005;28:1282-1288.

DCCT (Diabetes Control and Complications Trial) Research Group. The effect of intensive treatment of diabetes on the development and progression of longterm complications in insulin-dependent diabetes mellitus. $N$ Engl J Med. 1993;329:977-986.

DCCT (Diabetes Control and Complications Trial) Research Group. Effect of intensive diabetes treatment on the development and progression of long-term complications in adolescents with insulin-dependent diabetes mellitus: Diabetes Control and Complications Trial. J Pediatr. 1994;125:177-188.

Dixon AN, Bain SC. Nausea and vomiting due to insulin glargine in patient with type 1 diabetes mellitus. BMJ. 2005;330:455.

Dixon B, Chase HP, Burdick J, et al. Use of insulin glargine in children under age 6 with type 1 diabetes. Pediatr Diabetes. 2005;6:150-154.

Dixon S, Peters JR. Evaluating the 'real' cost-effectiveness of health technology: reconciling the public interest with patients' interests. Curr Med Res Opin. 2007;23(Suppl. 1):S1-S6.

Doyle EA, Weinzimer SA, Steffen AT, Ahern JA, Vincent M, Tamborlane WV. $A$ randomized, prospective trial comparing the efficacy of continuous subcutaneous insulin infusion with multiple daily injections using insulin glargine. Diabetes Care. 2004;27:1554-1558.

Eliaschewitz FG, Calvo C, Valbuena H, et al. Therapy in type 2 diabetes: insulin glargine vs. NPH insulin both in combination with glimepiride. Arch Med Res. 2006;37:495-501.

Fischer JS, McLaughlin T, Loza L, Beauchamp R, Schwartz S, Kipnes M. The impact of insulin glargine on clinical and humanistic outcomes in patients uncontrolled on other insulin and oral agents: an office-based naturalistic study. Curr Med Res Opin. 2004;20:1703-1710.

Fonseca V, Bell DS, Berger S, Thomson S, Mecca TE. A comparison of bedtime insulin glargine with bedtime neutral protamine hagedorn insulin in patients with type 2 diabetes: subgroup analysis of patients taking once-daily insulin in a mulitcenter, randomized, parallel group study. Am J Med Sci. 2004;328:274-280. 
Fritsche A, Schweitzer MA, Häring H-U; 4001 study group. Glimepiride combined with morning insulin glargine, bedtime neutral protamine hagedorn insulin, or bedtime insulin glargine in patients with type 2 diabetes. A randomized controlled trial. Ann Intern Med. 2003;138:952-959.

Fulcher GR, Gilbert RE, Yue DK. Glargine is superior to neutral protamine hagedorn for improving glycated haemoglobin and fasting blood glucose levels during intensive insulin therapy. Intern Med J. 2005;35:536-542.

Garcia-Garcia E, Galera R, Aguilera P, Cara G, Bonillo A. Long-term use of continuous subcutaneous insulin infusion compared with multiple daily injections of glargine in pediatric patients. $J$ Pediatr Endocrinol Metab. 2007;20:37-40.

Garg SK, Rosenstock J, Ways K. Optimized basal-bolus insulin regimens in type 1 diabetes: insulin glulisine versus regular human insulin in combination with basal insulin glargine. Endocr Pract. 2005;11:11-17.

Gerstein HC, Yale J-F, Harris SB, Issa M, Stewart JA, Dempsey E. A randomized trial of adding insulin glargine vs. avoidance of insulin in people with type 2 diabetes on either no oral glucose-lowering agents or submaximal doses of metformin and/or sulphonylureas. The Canadian INSIGHT (Implementing New Strategies with Insulin Glargine for Hypoglycaemia Treatment) study. Diabet Med. 2006;23:736-742.

Gomis R, Storms F, Conget I, Sinnassamy P, Davies M; AT.LANTUS study group. Improving metabolic control in sub-optimally controlled subjects with type 1 diabetes: comparison of two-treatment algorithms using insulin glargine. Diabetes Res Clin Pract. 2007;77:84-91.

Grima DT, Thompson MF, Sauriol L. Modelling cost effectiveness of insulin glargine for the treatment of type 1 and 2 diabetes in Canada. Phamacoeconomics. 2007;25:253-266.

Grimaldi A, Vialettes B, Blayo A, Brun JM, Halimi S. Comparison of dinner with bedtime administration of insulin glargine in type 1 diabetic patients treated with basal-bolus regimen. Diabetes Metab. 2007;33:121-128.

Gummerson I. An update on insulin analogues. Pharm J. 2006;277:169-172.

Hamann A, Matthaei S, Rosak C, Silvestre L; HOE 901/4007 study group. A randomized clinical trial comparing breakfast, dinner, or bedtime administration of insulin glargine in patients with type 1 diabetes. Diabetes Care. 2003;26:1738-1744.

Hathout EH, Fujishige L, Geach J, Ischandar M, Maruo S, Mace JW. Effect of therapy with insulin glargine (lantus) on glycemic control in toddlers, children, and adolescents with diabetes. Diabetes Technol Ther. 2003;5:801-806.

Heine RJ, Van Gaal LF, Johns D; GWAA study group. Exenatide versus insulin glargine in patients with suboptimally controlled type 2 diabetes: a randomized trial. Ann Intern Med. 2005;143:559-569.

Heinemann L, Linkeschova R, Rave K, Hompesch B, Sedlak M, Heise T. Time-action profile of the long-acting insulin analog insulin glargine (HOE901) in comparison with those of NPH insulin and placebo. Diabetes Care. 2000;23:644-649.

Herman WH, llag LL, Johnson SL, et al. A clinical trial of continuous subcutaneous insulin infusion versus multiple daily injections in older adults with type 2 diabetes. Diabetes Care. 2005;28:1568-1573.

Hershon KS, Blevins TC, Mayo CA, Rosskamp R. Once-daily insulin glargine compared with twice-daily NPH insulin in patients with type 1 diabetes. Endocr Pract. 2004;10:10-17.

Hirsch IB, Bode BW, Garg S, et al; Insulin Aspart CSII/MDI Comparison study group. Continuous subcutaneous insulin infusion (CSII) of insulin aspart versus multiple daily injection of insulin aspart/insulin glargine in type 1 diabetic patients previously treated with CSII. Diabetes Care. 2005;28:533-538.

HOE 901/2004 Study Investigators Group. Safety and efficacy of insulin glargine (HOE 901) versus NPH insulin in combination with oral treatment in type 2 diabetic patients. Diabet Med. 2003;20:545-551.

Home PD, Rosscamp R, Forjanic-Klapproth J, Dressler A; European Insulin Glargine study group. A randomized multicentre trial of insulin glargine compared with NPH insulin in people with type 1 diabetes, Diabetes Metab Res Rev. 2005;21:545-553.
IDF (International Diabetes Federation). Diabetes facts and figures. 2007a. Available at: http://www.idf.org/home/index.cfm?node=6 (accessed March 2007).

IDF (International Diabetes Federation). Global guideline for type 2 diabetes. 2007b. Available at: http://www.idf.org/home/index.cfm?unode= B7462CCB-3A4C-472C-80E4-710074D74AD3 (accessed March 2007).

Jacober SJ, Scism-Bacon JL, Zagar AJ. A comparison of intensive mixture therapy with basal insulin therapy in insulin-naïve patients with type 2 diabetes receiving oral antidiabetes agents. Diabetes Obes Metab. 2006;8:448-455.

Janka HU, Plewe G, Riddle MC, Kliebe-Frisch C, Schweitzer MA, YkiJärvinen $\mathrm{H}$. Comparison of basal insulin added to oral agents versus twicedaily premixed insulin as initial insulin therapy for type 2 diabetes. Diabetes Care. 2005;28:254-259.

Janka HU, Plewe G, Busch K. Combination of oral antidiabetic agents with basal insulin versus premixed insulin alone in randomized elderly patients with type 2 diabetes mellitus. J Am Geriatr Soc. 2007;55:182-188.

Kacerovsky-Bielesz G, Dressler A, Freunscht R. Long-term glycemic control with insulin glargine in type 2 diabetes. Diabetes Res Clin Pract. 2006;71:184-191.

Kann $\mathrm{PH}$, Wascher T, Zackova V, et al. Starting insulin therapy in type 2 diabetes: twice-daily biphasic insulin aspart 30 plus metformin versus oncedaily insulin glargine plus glimepiride. Exp Clin Endocrinol Diabetes. 2006;114:527-532.

Karges B, Muche R, Riegger I, Moritz M, Heinze E, Debatin KM, et al. Injection of acidic or neutral insulin and pain: a single-center, prospective, controlled, noninterventional study in pediatric patients with type 1 diabetes mellitus. Clin Ther. 2006;28:2094-2101.

Kennedy L, Herman WH, Strange P, Harris A; GOAL A1C Team. Impact of active versus usual algorithmic titration of basal insulin and point-of-care versus laboratory measurement of $\mathrm{HbA}_{1 \mathrm{c}}$ on glycemic control in patients with type 2 diabetes: the Glycemic Optimization with Algorithms and Labs at Point of Care (GOAL A1C) trial. Diabetes Care. 2006;29:1-8.

Lechleitner M, Roden M, Haehling E, Mueller M. Insulin glargine in combination with oral antidiabetic drugs as a cost-equivalent alternative to conventional insulin therapy in type 2 diabetes mellitus. Wien Klin Wochenschr. 2005;117:593-598.

Lepore M, Pampanelli S, Fanelli C, et al. Pharmacokinetics and pharmacodynamics of subcutaneous injection of long-acting human insulin analog glargine, NPH insulin, and ultralente human insulin and continuous subcutaneous infusion of insulin lispro. Diabetes. 2000;49:2142-2148.

Luzio SD, Beck P, Owens DR. Comparison of the subcutaneous absorption of insulin glargine (Lantus ${ }^{\circledR}$ ) and NPH insulin in patients with type 2 diabetes. Horm Metab Res. 2003;35:434-438.

Malone JK, Kerr LF, Campaigne BN, Sachson RA, Holcombe JH; Lispro Mixture-Glargine study group. Combined therapy with insulin lispro mix 75/25 plus metformin or insulin glargine plus metformin: a 16-week, randomized, open-label, crossover study in patients with type 2 diabetes beginning insulin therapy. Clin Ther. 2004;26:2034-2044.

Malone JK, Bai S, Campaigne BN, Reviriego J, Augendre-Ferrante B. Twice-daily pre-mixed insulin rather than basal insulin therapy alone results in better overall glycemic control in patients with type 2 diabetes. Diabet Med. 2005;22:374-381.

Manini R, Forlani G, Moscatiello S, Zannoni C, Marzocchi R, Marchesini G. Insulin glargine improves glycemic control and health-related quality of life in type 1 diabetes. Nutr Metab Cardiovasc Dis. 2007. In press. DOI:10.1016/j.numecd.2006.07.001.

Massi Benedetti MM, Humburg E, Dressler A, Ziemen M. A one-year, randomized, multicentre trial comparing insulin glargine with NPH insulin in combination with oral agents in patients with type 2 diabetes. Horm Metab Res. 2003;35:189-196.

McEwan P, Poole CD, Tetlow T, Holmes P, Currie CJ. Evaluation of the costeffectiveness of insulin glargine versus NPH insulin for the treatment of type 1 diabetes in the UK. Curr Med Res Opin. 2007a;23(Suppl. 1):S7-S19. 
McEwan P, Poole CD, Tetlow T, Holmes P, Currie CJ. Evaluation of the cost-effectiveness of insulin glargine versus NPH insulin for the treatment of type 2 diabetes in the UK. Curr Med Res Opin. 2007b;23(Suppl. 1):S21-S31.

McKeage K, Goa KL. Insulin glargine: a review of its therapeutic use as a long-acting agent for the management of type 1 and 2 diabetes mellitus. Drugs. 2001;61:1599-1624.

Meneghini L, Schwartz S, Strange P, Oster G. Health-related quality of life and costs of receiving add-on therapy with insulin glargine or pioglitazone in patients with type 2 diabetes. Diabetologia. 2006;49(Suppl. 1):543. Abstract 0894.

Milicevic Z, Raz I, Strojek K, et al; HEART2D Study. Hyperglycemia and its effect after acute myocardial infarction on cardiovascular outcomes in patients with type 2 diabetes mellitus (HEART2D) study design. $J$ Diabetes Complications. 2005;19:80-87.

Mortensen HB, Hougaard P. Comparison of metabolic control in a crosssectional study of 2,873 children and adolescents with IDDM from 18 countries. Hvidøre Study Group on Childhood Diabetes. Diabetes Care. 1997;20:714-720.

Nathan DM, Cleary PA, Backlund JY, et al; Diabetes Control and Complications Trial/ Epidemiology of Diabetes Interventions and Complications (DCCT/EDIC) Study Research Group. Intensive diabetes treatment and cardiovascular disease in patients with type 1 diabetes. N Engl J Med. 2005;353:2643-2653.

NICE (National Institute for Health and Clinical Excellence). Technology Appraisal Guidance 53. Guidance on the use of long-acting analogs for the treatment of diabetes - insulin glargine. London: NICE; December 2002. Available at:

http://guidance.nice.org.uk/TA53/guidance/pdf/English/download.dspx (accessed January 2007).

Owens DR, Coates PA, Luzio SD, Tinbergen JP, Kurzhals R.

Pharmacokinetics of ${ }^{125}$ /-labeled insulin glargine (HOE 901) in healthy men. Comparison with NPH insulin and the influence of different subcutaneous injection sites. Diabetes Care. 2000;23:813-819.

Pan C-Y, Sinnassamy P, Chung K-D, Kim K-W; LEAD Study Investigators Group. Insulin glargine versus NPH insulin therapy in Asian type 2 diabetes patients. Diabetes Res Clin Pract. 2007;76:111-118.

Physicians' Desk Reference. Montvale, NJ: Thomson Healthcare; 2007. Available at: http://www.pdr.net (accessed June 2007).

Pieber TR, Eugene-Jolchine I, Derobert E. Efficacy and safety of HOE 901 versus NPH insulin in patients with type 1 diabetes. The European Study Group of HOE 901 in type 1 diabetes. Diabetes Care. 2000;23:157-162.

Pieber TR, Treichel H-C, Hompesch B, et al. Comparison of insulin detemir and insulin glargine in subjects with type 1 diabetes using intensive insulin therapy. Diabet Med. 2007;24:635-642.

Pinhas-Hamiel O, Zeitler P. The global spread of type 2 diabetes mellitus in children and adolescents. J Pediatr. 2005;146:693-700.

Poole CD, Tetlow T, McEwan P, Holmes P, Currie CJ. The prescription cost of managing people with type 1 and type 2 diabetes following initiation of treatment with either insulin glargine or insulin detemir in routine general practice in the UK: a retrospective database analysis. Curr Med Res Opin. 2007;23(Suppl. 1):S41-S48.

Porcellati F, Rossetti P, Pampanelli S, et al. Better long-term glycemic control with the basal insulin glargine as compared with NPH in patients with type 1 diabetes mellitus given meal-time lispro insulin. Diabet Med. 2004;21:1213-1220.

Powers AC. Diabetes mellitus. In: Kasper DL, Fauci AS, Longa DL, Braunwald E, Hauser SL, Jameson JL, eds. Harrison's principles of internal medicine. 16th ed. New York: McGraw-Hill; 2005, pp. 2152-2180.

Profit L. Exubra ${ }^{\circledR}$ (inhaled insulin): an evidence-based review of its effectiveness in the management of diabetes. Core Evidence. 2005;1:90-101.

Raskin P, Klaff L, Bergenstal R, Hallé J-P, Donley D, Mecca T. A 16-week comparison of the novel insulin analog insulin glargine (HOE 901) and NPH human insulin used with insulin lispro in patients with type 1 diabetes. Diabetes Care. 2000;23:1666-1671.
Raskin P, Allen E, Hollander P, et al; INITIATE Study Group. Initiating insulin therapy in type 2 diabetes: a comparison of biphasic and basal insulin analogs. Diabetes Care. 2005;28:260-265.

Raskin PR, Hollander PA, Lewin A, Gabbay RA, Bode B, Garber AJ; INITIATE Study Group. Basal insulin or premix analogue therapy in type 2 diabetes patients. Eur J Intern Med. 2007;18:56-62.

Ratner RE, Hirsch IB, Neifing JL, Garg SK, Mecca TE, Wilson CA. Less hypoglycemia with insulin glargine in intensive insulin therapy for type 1 diabetes. US Study Group of Insulin Glargine in Type 1 Diabetes. Diabetes Care. 2000;23:639-643.

Ray JA, Valentine WJ, Roze S, et al. Insulin therapy in type 2 diabetes patients failing oral agents: cost-effectiveness of biphasic insulin aspart 70/30 vs insulin glargine in the US. Diabetes Obes Metab. 2007;9:103-113.

Reynolds LR, Kingsley FJ, Karounos DG, Tannock LR. Differential effects of rosiglitazone and insulin glargine on inflammatory markers, glycemic control, and lipids in type 2 diabetes. Diabetes Res Clin Pract. 2007;77:180-187.

Riddle MC, Rosenstock J, Gerich J; Insulin Glargine 4002 Study Investigators. The treat-to-target trial: randomized addition of glargine or human NPH insulin to oral therapy of type 2 diabetic patients. Diabetes Care. 2003;26:3080-3086.

Roach P, Malone JK. Comparison of insulin lispro mixture 25/75 with insulin glargine during a 24-h standardized test-meal period in patients with type 2 diabetes. Diabet Med. 2006;23:743-749.

Rosenstock J, Park G, Zimmerman J; US Insulin Glargine (HOE 901) Type 1 Diabetes Investigator Group. Basal insulin glargine (HOE 901) versus NPH insulin in patients with type 1 diabetes on multiple daily insulin regimens. Diabetes Care. 2000;23:1137-1142.

Rosenstock J, Schwartz SL, Clark CM Jr, Park GD, Donley DW, Edwards MB. Basal insulin therapy in type 2 diabetes: 28-week comparison of insulin glargine (HOE 901) and NPH insulin. Diabetes Care. 2001;24:631-636.

Rosenstock J, Dailey G, Massi-Benedetti M, Fritsche A, Lin Z, Salzman A. Reduced hypoglycemia risk with insulin glargine: a meta-analysis comparing insulin glargine with human NPH insulin in type 2 diabetes. Diabetes Care. 2005;28:950-955.

Rosenstock J, Sugimoto D, Strange P, Stewart JA, Soltes-Rak E, Dailey G. Triple therapy in type 2 diabetes: insulin glargine or rosiglitazone added to combination therapy of sulfonylurea plus metformin in insulin-naïve patients. Diabetes Care. 2006;29:554-559.

Rossetti P, Pampanelli S, Fanelli C, et al. Intensive replacement of basal insulin in patients with type 1 diabetes given rapid-acting insulin analog at mealtime: a 3-month comparison between administration of NPH insulin four times daily and glargine insulin at dinner or bedtime. Diabetes Care. 2003;26:1490-1496.

Schober E, Schoenle E, Van Dyk J, Wernicke-Panten K; Pediatric Study Group of Insulin Glargine. Comparative trial between insulin glargine and $\mathrm{NPH}$ insulin in children and adolescents with type 1 diabetes mellitus. J Pediatr Endocrinol Metab. 2002;15:369-376.

Scholtz HE, Pretorius SG, Wessels DH, Becker RH. Pharmacokinetic and glucodynamic variability: assessment of insulin glargine, NPH insulin and insulin ultralente in healthy volunteers using a euglycemic clamp technique. Diabetologia. 2005;48:1988-1995.

Schreiber SA, Haak T. Insulin glargine benefits patients with type 2 diabetes inadequately controlled on oral antidiabetic treatment: an observational study of everyday practice in 12,216 patients. Diabetes Obes Metab. 2007;9:31-38.

Secnik Boye K, Matza LS, Oglesby A, et al. Patient-reported outcomes in a trial of exenatide and insulin glargine for the treatment of type 2 diabetes. Health Qual Life Outcomes. 2006;4:80.

Skyler JS. Effects of glycemic control on diabetes complications and on the prevention of diabetes. Clin Diabetes. 2004;22:162-166.

Standl E, Maxeiner S, Raptis S; HOE 901/4009 Study Group. Once-daily insulin glargine administration in the morning compared to bedtime in 
Insulin glargine | clinical impact review

combination with morning glimepiride inpatients with type 2 diabetes: an assessment of treatment flexibility. Horm Metab Res. 2006;38:172-177.

Triplitt C, Glass L, Miyazaki Y, et al. Comparison of glargine insulin versus rosiglitazone addition in poorly controlled type 2 diabetic patients on metformin plus sulfonylurea. Diabetes Care. 2006;29:2371-2377.

UKPDS (UK Prospective Diabetes Study). Intensive blood-glucose control with sulphonylureas or insulin compared with conventional treatment and risk of complications in patients with type 2 diabetes (UKPDS 33). Lancet. 1998a;352:837-853.

UKPDS (UK Prospective Diabetes Study). Effect of intensive blood-glucose control with metformin on complications in overweight patients with type 2 diabetes (UKPDS 34). Lancet. 1998b;352:854-865.

Valentine WJ, Palmer AJ, Erny-Albrecht KM, et al. Cost-effectiveness of basal insulin from a US health system perspective: comparative analyses of detemir, glargine, and NPH. Adv Ther. 2006;23:191-207.

Vinik Al, Zhang Q. Adding insulin glargine versus rosiglitazone: health-related quality-of-life impact in type 2 diabetes. Diabetes Care. 2007;30:795-800.

Warren E, Weatherley-Jones E, Chilcott J, Beverley C. Systematic review and economic evaluation of a long-acting insulin analogue, insulin glargine. Health Technol Assess. 2004;8:iii, 1-57.

WHO (World Health Orgaization). Diabetes mellitus fact sheet no. 312. September 2006. Available at http://www.who.int/inf (accessed January 2007).

Witthaus E, Stewart J, Bradley C. Treatment satisfaction and psychological well-being with insulin glargine compared with NPH in patients with type 1 diabetes. Diabet Med. 2001;18:619-625.

Yki-Järvinen, Dressler A, Ziemen M; HOE 901/3002 Study Group. Less nocturnal hypoglycemia and better post-dinner glucose control with bedtime insulin glargine compared with bedtime NPH insulin during insulin combination therapy in type 2 diabetes. Diabetes Care. 2000;23:1130-1136. Yki-Järvinen H, Kauppinen-Mäkelin R, Tiikkainen M, et al. Insulin glargine or NPH combined with metformin in type 2 diabetes: the LANMET study.

Diabetologia. 2006;49:442-451.

Correspondence: Steve Clissold, Content Ed Net

Communications S.L., C. Maestro Lassalle 36, 28016 Madrid, Spain or at steve.clissold@contentednet.com 